ARGONNE NATIONAL LABORATORY

9700 South Cass Avenue, Argonne, Illinois 60439

ANL/EES-TM--292

DE86 004965

ANL/EES-TM-292

RADIOACTIVE WASTE ISOLATION IN SALT:

PEER REVIEW OF WESTINGHOUSE ELECTRIC CORPORATION'S

REPORT ON REFERENCE CONCEPTUAL DESIGNS

FOR A REPOSITORY WASTE PACKAGE

by

D.M. Rote, A.B. Hull, G.S. Was ${ }^{*}$ D.D. Macdonald, ${ }^{\ddagger}$ B.E. Wilde, J.E. Russell," J. Kruger,**

W. Harrison, and D.F. Hambley

Energy and Environmental Systems Division

Geoscience and Engineering Group

October 1985

work sponsored by

U.S. DEPARTMENT OF ENERGY

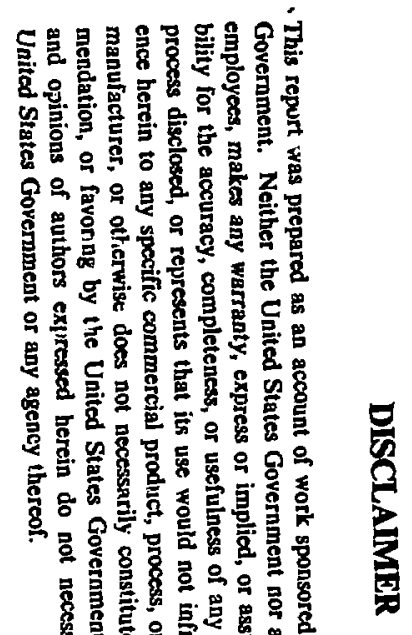

*University of Michigan

${ }^{\ddagger}$ SRI International, Menlo Park, Ca]if.

Ohio State University

\# Texas A\& M University

**Johns Hopkins University

Salt Repository Project Office 


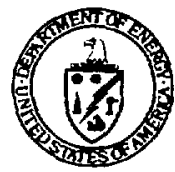

Department of Energy

Chicago Operations Office

Salt Repository Project Office

505 King Avenue

Columbus, Ohio 43201-2693

October 16, 1985

NOTICE TO READERS

At the request of the Salt Repository Project Office (SRPO), Argonne National Laboratory carried out a review of a Westinghouse Electronic Corporation report entitled "Waste Package Reference Conceptual Designs for a Repository in Sa7t," WTSD-TM-001, revision $A^{*}$. This report includes designs for: the reference defense high level waste form from the Savannah River Plant; an optimized commercial high level waste form; and, spent fuel which has been disassembled and compacted into a circular bundle. It has provided a sound basis for the cievelopment of the advanced waste package conceptual design.

Specific instructions were provided to the review panel. The panel also reviewed the document from a broad point of view. Valuable comments were provided by the panel. Resolution of the comments and recommendations are included in Appendix $C$ of this report.

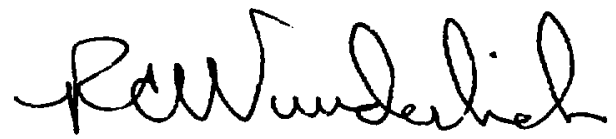

R.C. Wunderlich

SRP0:KKW: $\max : 9126 \mathrm{~B}$

ST\# 023-86

* A microfiche copy of this report is attached to the inside back cover of this report. 


\section{PREVIOUSLY PUBLISHED REPORTS IN THE SERIES}

"RADIOACTIVE WASTE ISOLATION IN SALT" (Cont'd)

ANL/ES-1 47

ANL/EES-TM-290
Rationale and Methodology for Argonne-Conducted Reviews of Site Characterization Programs (July 1985)

Geochemistry of Brine in Rock Salt in Temperature Gradients and Gamma-Radiation Fields -- A Selective Annotated Bibliography (July 1985) 


\section{FOREWORD}

Documents are being submitted to the Salt Repository Project Office (SRPO) of the U.S. Department of Energy (DOE) by Battelie Memorial Institute's Office of Nuclear Waste Isolation (ONWI) to satisfy milestones of the Salt Repository Project of the Civilian Radioactive Waste Management Program. Some of these documents are being reviewed by multidisciplinary groups of peers to ensure DOE of their adequacy and credibility. Adequacy of documents refers to their ability to meet the standards of the U.S. Nuclear Regulatory Commission, as enunciated in 10 CF R Part 60, and the requirements of the National Environmental Policy Act and the Nuclear Waste Policy Act of 1982. Credibility of documents refers to the validity of the assumptions, methods, and conclusions, as well as to the completeness of coverage.

Since late 1982, Argonne National Laboratory has been under contract to DOE to conduct multidisciplinary peer reviews of program plans and reports covering research and development activities related to siting and constructing a mined repository in salt for high-level radioactive waste. This report summarizes Argonne's review of Waste Package Reference Conceptual Designs for a Repository in Salt, WTSD-TME-001, Revision A. The report is dated Novembe: $i 984$ and was prepared for ONWI by Westinghouse Electric Corporation.

Argonne was requested by DOE to review this report on January 24, 1985 (see App. A). The review procedure involved obtaining written cornments on the report from four members of Argonne's core peer review staff and from five external peer reviewers who are experts in relevant research areas. The peer review nanel met at Argonne on February 25, 1985, and reviewer comments were integrated into this report by the review session chairman, with the assistance of Argonne's core peer review staff. All of the peer review panelists have concurred in the way in which their comments are presented in this report (see App. B). A draft of this report was sent to SRPO on March 21, 1985. The resolution of ONWI's response to this review report is detailed in App. C. 


\section{PREVIOUSLY PUBLISHED REPORTS IN THE SERIES}

\section{"RADIOACTIVE WASTE ISOLATION IN SALT"}

ANL/EES-TM-242 Peer Review of the Office of Nuclear Waste Isolation's Geochemical Program Plan (Feb. 1984)

ANL/EES-TM-243 Peer Review of the Office of Nuclear Waste Isolation's Socioeconomic Program Plan (Feb. 1984) (revised July 1984)

ANL'EES-TM-246 Peer Review of the Office of Nuclear Waste Isolation's Plans for Repository Performance Assessment (May 1994)

ANL/EES-TM-254 Peer Review of the Office of Nuclear Waste Isolation's Reports on Preferred Repository Sites within the Palo Duro Basin, Texas (June 1984)

ANL/EES-TM-256 Special Advisory Report on the Status of the Office of Nuclear Waste Isolation's Plans for Repository Performance Assessment (Oct. 1983)

ANL/EES-TM-258 Peer Review of the Office of Nuclear Waste Isolation's Plan to Decommission and Reclaim Exploratory Shafts and Related Facilities (July 1984)

ANL/EES-TM-259

Peer Review of the Office of Nuclear Waste Isolation's Final Report on the Organic Geochemistry of Deep Groundwaters from the Palo Duro Basin, Texas (Aug. 1984)

ANL/EES-TM 260

Peer Review of the Texas Bureau of Economic Geology's Report on the Petrographic, Stratigraphic, and Structural Evidence for Dissolution of Upper Permian Bedded Salt, Texas Panhandle (Aug. 1984)

ANL/EES-TM-261

Peer Review of the Office of Nuclear Waste Isolation's Report on Functional Design Criteria for a Repository for High-Level Radioactive Waste (Aug. 1984)

ANL/EES-TM-262 Peer Review of the D'Appolonia Report on Schematic Designs for Penetration Seals for a Repository in the Permian Basin, Texas (Sept. 1984)

ANL/EES-TM-263 Peer Review of the Office of Nuclear Waste Isolation's Reports on Muliifactor Life Testing of Waste Package Materials (Sept. 1984) 


\section{CONTENTS}

PEER REVIEW PANEL MEMBERS $\ldots \ldots \ldots \ldots \ldots \ldots \ldots \ldots \ldots \ldots \ldots \ldots \ldots \ldots \ldots \ldots \ldots \ldots$

SUMMARY OF RECOMMENDATIONS $\ldots \ldots \ldots \ldots \ldots \ldots \ldots \ldots \ldots \ldots \ldots \ldots \ldots \ldots$

1 INTRODUCTION $\ldots \ldots \ldots \ldots \ldots \ldots \ldots \ldots \ldots \ldots \ldots \ldots \ldots \ldots \ldots \ldots \ldots \ldots \ldots \ldots \ldots$

2 REGULATORY ISSUES $\ldots \ldots \ldots \ldots \ldots \ldots \ldots \ldots \ldots \ldots \ldots \ldots \ldots \ldots \ldots \ldots \ldots \ldots$

3 SUGGESTIONS TO IMPROVE PRESENTATION ..................... 12

3.1 Introduction $\ldots \ldots \ldots \ldots \ldots \ldots \ldots \ldots \ldots \ldots \ldots \ldots \ldots \ldots \ldots \ldots \ldots \ldots \ldots \ldots \ldots \ldots \ldots$

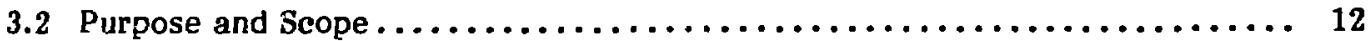

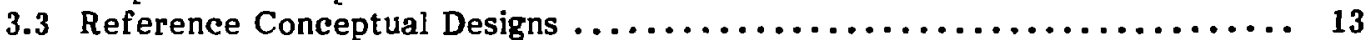

3.4 Waste Package .................................... 13

3.5 Proprietary Computer Codes ........................... 13

3.6 Consistency of Design Criteria $\ldots \ldots \ldots \ldots \ldots \ldots \ldots \ldots \ldots \ldots \ldots \ldots \ldots \ldots \ldots$

3.7 Test Program ................................... 14

4 TECHNICAL CONSIDERATIONS ......................... 15

4.1 Materials Selection ................................ 15

4.1 .1 Overpack Materials .................................. 15

4.1.2 Waste Form Canister Materials ...................... 17

4.2 Corrosion Analysis $\ldots \ldots \ldots \ldots \ldots \ldots \ldots \ldots \ldots \ldots \ldots \ldots \ldots \ldots \ldots \ldots \ldots \ldots \ldots \ldots$

4.2.1 General Corrosion ............................. 18

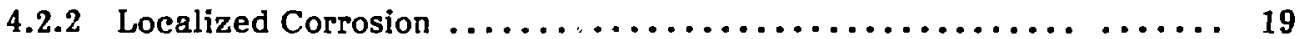

4.2.3 Data Extrapolation ............................ 21

4.2 .4 Corrosion Allowance ............................ 21

4.2.5 Testing and Verification Program ...................... 22

4.3 Brine Migration and the Local Environment .................... 23

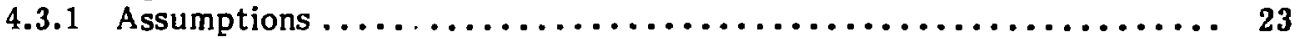

4.3 .2 Models ..................................... 24

4.3 .3 Data Needs and Testing Program ..................... 24

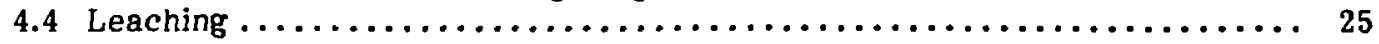

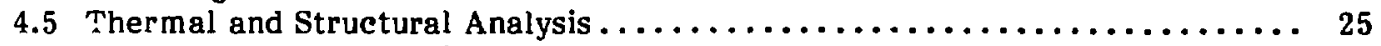

4.5 .1 Thermal Analysis ............................. 26

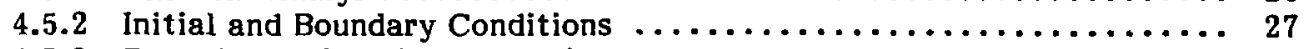

4.5.3 Repository Material Properties ....................... 27

4.5.4 Structural Performance $\ldots \ldots \ldots \ldots \ldots \ldots \ldots \ldots \ldots \ldots \ldots \ldots \ldots \ldots \ldots \ldots$

4.5.5 Thermal Expansion of Salt and Effects o Creep on

Waste Packages .............................. 27

4.6 Retrievability $\ldots \ldots \ldots \ldots \ldots \ldots \ldots \ldots \ldots \ldots \ldots \ldots \ldots \ldots \ldots \ldots \ldots \ldots \ldots \ldots$

5 U.S. DEPARTMENT OF ENERGY REVIEW QUESTIONS .............. 30

6 PAGE-BY-PAGE COMMENTARY $\ldots \ldots \ldots \ldots \ldots \ldots \ldots \ldots \ldots \ldots \ldots \ldots \ldots \ldots$

REFERENCES $\ldots \ldots \ldots \ldots \ldots \ldots \ldots \ldots \ldots \ldots \ldots \ldots \ldots \ldots \ldots \ldots \ldots \ldots \ldots \ldots \ldots \ldots$

APPENDIX A: U.S. Department of Eneryy Letter Requesting Peer Review ....... 55 


\section{CONTENTS (Cont'd)}

APPENDIX B: Concurrence Sheet $\ldots \ldots \ldots \ldots \ldots \ldots \ldots \ldots \ldots \ldots \ldots \ldots \ldots \ldots$

APPENDIX C: Resolution of ONWI Responses to the Peer Review Panel's

Recommendations and Page-by-Page Comments ............63

APPEndiX D: Credentials ci Peer Review Panel Members ............... 85

A microfiche copy of the following unpublished report is attached to the inside back cover of this report: Waste Package Reference Conceptual Designs for a Repository in Salt, Westinghouse Electric Corporation, Waste Technology Services Division, Madison, Penn., WTSD-TME-001, Revision A (Nov. 1984). 


\title{
RADIOACTIVE WASTE ISOLATION IN SALT:
}

\section{PEER REVIEW OF WESTINGHOUSE ELECTRIC CORPORATION'S REPORT ON REFERENCE CONCEPTUAL DESIGNS FOR A REPOSITORY WASTE PACKAGE}

\author{
by \\ D.M. Rote, A.B. Hull, G.S. Was, D.D. Macdonald, \\ B.E. Wilde, J.E. Russell, J. Kruger, \\ W. Harrison, and D.F. Hambley
}

\section{SUMMARY OF RECOMMENDATIONS}

This report documents the findings of the peer panel constituted by Argonne National Laboratory to review Revision A of Westinghouse Electric Corporation's report entitled Waste Package Reference Conceptual Designs for a Repository in Salt. The panel determined that the reviewed report does not provide reasonable assurance that U.S. Nuclear Regulatory Commission (NRC) requirements for waste packages will be met by the proposed design. It also found that it is premature to call ine design a "reference design," or even a "reference conceptual design." This review report provides guidance for the preparation of a more acceptable design document. The following recommendations have been abstracted from the body of this report.

In the area of regulations, the authors of a revised report should:

1. Define the correspondence between NRC regulations and those listed in App. F. The absence of such correspondence is a serious shortcoming of the document.

2. Add a few appropriately placed statements in Sec. 5 that will tie the performance of the waste package to the specific requirements described in Sec. 3.1, and to specific sections of Title 10, Part 60, of the Code of Federal Regulations (10 CFR 60) and other published regulations.

3. Indicate whether the computer codes discussed in the document are in the public domain. If not, their use will not be accepted by NRC.

4. Refer to NRC technical positions on evaluation of waste package performance for guidance in preparing waste package conceptual designs. In particular, the major issues identified by Davis and Schweitzer (1983) should be reviewed. The uncertainties in the data and calculations should be at least qualitatively discussed. 
5. Evaluate the required development programs in terms of stated NRC pasitions to determine if the information necessary to support a licensing application and to demonstrate reasonable assurance will be obtained.

To improve the technical content of the report, the authors should:

\section{Materials Selection}

6. Reorder the materials selection criteria so that a fail-safe criterion ranks above all other criteria, including cost effectiveness. Currently, cost effectiveness ranks too high in importance.

7. Critically review the reordered criteria and justify choosing low carbon steel if, in fact, it remains the material of choice. The current report gives the impression that materials selection is a foregone conclusion and not worth careful consideration and documentation.

8. Develop a set of design requirements for the waste forms and canisters, and use it to select materials. The current report almost totally ignores these components.

9. Retain alternative material choices as backups in the event that the reference choice is inadequate.

10. Incorporate heat-affected-zone hardness considerations in the materials selection process. Failing to consider the heat-affected zone may prove to be the "Achilles' heel" of the reference design.

\section{Corrosion Analysis}

11. Discuss the major factors known to influence general corrosion and indicate which of these are applicable to the present problem and which are not, and why.

12. Review the extensive literature on corrosion of carbon steel in high-temperature aqueous solutions, and consider both linear and autocatalytic corrosion of carbon steel in high-temperature brines.

13. Reexamine the importance of the various known forms of localized corrosion, and justify why certain forms, if any, can be ignored. In particular, hydrogen embrittlement and stress corrosion cracking in the heat-affected zones of weldments should be addressed. 
14. Take into account expected temperatures, as well as chemical and radiation stresses, and justify why the pitting corrosion depth is expected to be less than or equal to two times the general corrosion depth.

15. Apply statistical analysis to pitting data to estimate expected maximum pitting depth.

16. Reexamine the role of radiation effects on corrosion kinetics and on production of chemical species that enhance corrosion or leaching processes, and determine whether any of the effects can reasonably be ignored. In particular, provide better support for the assertion that gamma- and neutron-radiolysis of brine are likely to have only a negligible effect on the corrosion of carhon steel.

17. Reexamine the region of Eh-pH space for iron at expected waste package temperatures to determine whether iron is in the active or passive region. The report uses an Eh-pH diagram (Fig. B-1) for $25^{\circ} \mathrm{C}$ and then misinterprets the results.

18. Correct the assumption that the only compound present in the gaseous phase is pure water. Also, substantiate the claim that gas-phase corrosion is unimportant.

\section{Corrosion Testing and Verification Program}

19. Develop a list of assumptions and explain their status with regard to the need for short-term testing and long-term verification.

20. Include materials other than carbon steel in the program, in case carbon steel proves inadequate.

21. Extend the long-term verification program until the end of the retrievability period. Corrective action may be necessary.

22. Critically evaluate whether data obtained from tropical seawater of relatively low ionic strength and probably at room temperature have any relevance to brines of high ionic strength at elevated temperatures.

23. Reexainine the procedure for computing the corrosion allowance in light of the above critical evaluation of the relevance of data from tropical seawater and of the various concerns discussed in Secs. 4 and 6 of this report.

24. Add testing to relate the microstructure of steel in the heataffected zone to localized and galvanic corrosion processes. 
25. Place added emphasis on problems of pitting and crevice corrosion, stress corrosion cracking, and hydrogen embrittlement, as well as on the role of various corrosive chemical species.

20. Place added emphasis on the effects of radiation on corrosion kinetics, protective films, and production of species that may subsequently degrade the overpack and possibly the canister and waste form. The concept of pitting potential should be evaluated in terms of its applicability to the present problem and how such a potential would be affected by radiolytic oxidizers.

27. Incorporate a properly based statistical analysis of pitting attack because the overpack is most likely to be penetrated first by this form of corrosion.

28. Place more emphasis on linear and autocatalytic corrosion of carbon steel in high-temperature brines because these forms of attack are known to lead to extremely high corrosion rates.

29. Add a test matrix in which the reference temperature is about $250^{\circ} \mathrm{C}$. The independence of all variables with respect to temperature should te tested.

30. Develop and test a procedure to extrapolate test resiits to 1000 years.

\section{Brine Migration Characterization of the Local Repository Environment}

31. Update the references on brine migration mudeling.

32. Evaluate the importance of all known brine migration mechanisms, including vapor/liquid inclusion migration and stressgradient migration. Use a coupled transport mechanism approach, or demonstrate that the separate mechanisms approach is indeed conservative.

33. Take into account sources of water or brine ciher than liquid brine inclusions. Hydrated minerals and hygroscopic water should be included.

34. Incorporate the effects of radiation on brines. Review the extensive literature on this subject.

35. Discuss why $30 \mathrm{~L}$ was chosen as the upper limit for brine availability and give appropriate references.

36. Elaborate on why "there is a good chance that radiation effects need not be simulated as is planned for some of the Asse emplacements." 
37. Provide a better definition for the leaching test matrix, and justify the parameter types and values.

38. Discuss the added protection, if any, that Zircaloy-clad fuel rods might offer. Data needs with respect to the long-term performance of Zircaloy-clad fuel rods should be discussed. The authors take no credit for such protection.

39. Provide evidence over the full range of repository conditions that the overpack corrosion products are "stable, insoluble, [and] inert to the designated waste form."

\section{Thermal and Structural Analysis}

40. Clarify the assumptions made in the thermal analysis. For example, in the graphs of temperature versus time, identify all the conditions. Also, specify all the bounuary conditions and their relationship to those found in the literature.

41. Incorporate results from the Avery Island mine heater tests in the discussion of thermally induced stresses.

42. Discuss the applicability of the "coefficient of thermal expansion" concept to salt.

43. Provide a more realis $t$ ic analysis of heat transfer in consolidated solid fuel waste forms.

\section{Retrievability}

44. Justify more adequately why removal of the waste form and canister is better than removal of the waste package by overcoring. The inability to inspect the overpack for corrosion damage if only the waste form and canister are retrieved should be taken into account, as should exposure of workers to radiation from the uncovered waste form and canister.

The report should also be revised, augmented, and updated to reflect the following editorial changes:

45. Use SI units throughout.

46. Include a glossary of terms and a list of acronyms, and avoid jargon.

47. Add a section on the purpose and scope of the report, and clarify the nature of the document and its relationship to earlier related documents. 
48. Carefully define such terms as "waste package," "reference conceptual design," and "baselining," and use them consistently.

49. Consider adopting the new Common Terminology of Waste Package Components (Stein, 1985).

50. Carefully define and justify all design requirements and considerations, such as the importance of general versus local corrosion and the use of scenarios where there is limited versus unlimited availability of water or brine.

51. Avoid making statements of fact unless they are substantiated with references.

52. Reference all sources of data given in the text and tables. 


\section{INTRODUCTION}

Development of a reference waste package design suitable for a repository in salt for permanent isolation of high-level radioactive waste is one of the major tasks of the Salt Repository Project administered by the U.S. Department of Energy (DOE). The task, undertaken by Westinghouse Electric Corporation, is documented in a 1984 revision of a report prepared for Battelle Memorial Institute's Office of Nuclear Waste Isolation (ONWI) entitled Waste Package Reference Conceptual Designs for a Repository in Salt.

Argonne National Laboratory conducted a peer review of the Westinghouse report at the request of DOE's Salt Repository Project Office (SRPO). Written critiques of the report were obtained from four members of Argonne's core peer review staff and from five external experts. The four Argonne members met with one of the external reviewers and reviewed the written comments. The chairman of the peer review session then drafted the present report, with the assistance of Argonne's core peer review staff. The draft was then circulated to all reviewers for corrections, changes, and concurrence. The reviewers did not contact ONWI personnel, and none of the reviewers have been involved in any programs sponsored by DOE or directed by ONWI such that their participation in the review could be construed as a conflict of interest.

Although no specific guidance was provided to Argonne by SRPO on how the review was to be conducted, a set of questions was prepared by SRPO to assist in the review process (see App. A). These questions did not limit in any way the nature or extent of comments piovided by reviewers.

The main emphasis in this review report is on technical considerations, which are presented in Sec. 4. Section 6 is a comprehensive page-by-page listing of adritional technical and editorial comments. In general, the term "reference conceptual design" caused considerable confusion among the $r$ viewers because it had not been defined. The term is subject to several interpretations. In this review report, it was taken to mean a workable design that could be adopted as is, but which could aiso be used as a reference for comparing alternative designs. Of course, if a design is not workable, then it is meaningless to use it for comparison purposes. 


\section{REGULATORY ISSUES}

Several federal agencies have developed regulations pertinent to the construction, operation, and performance of repositories for permanent isolation of highlevel radioactive waste, and most such regulations refer directly or indirectly to the waste package. The regulations of most immediate concern are those developed by the U.S. Nuclear Regulatory Commission (NRC) and contained in Title 10, Part 60, of the Code of Federal Regulations (10 CFR 60) (U.S. Nuclear Regulatory Commission, 1984a). Although a number of revisions to $10 \mathrm{CFR} 60$ were recently proposed (U.S. Nuclear Regulatory Commission, 1985), none of these alter the technical criteria for waste packages contained in Subpart E.

Although Sec. 3.1 of the reviewed report diseusses regulatory requirements for waste package designs, NRC regulations are not mentioned. The discussed requirements are derived from those presented in an earlier Westinghouse document and in previously published DOE and ONW1 reports describing waste package design criteria and objectives. Although these documents should generally reflect current NRC reguletions, the discussion in Sec. 3.1 should refer to appropriate sections of 10 CFR 60 to explicitly demonstrate that eppropriate regulations were considered.

Sections $60.111,60.113,60.131$, and 60.135 of $10 \mathrm{CFR} 60$ contain reguiatory requirements and criteria related to waste package design. Although the major points in these requirements are alluded to in Sec. 3.1, appropriate sections of $10 \mathrm{CFR} 6 \mathrm{C}$ should be cited. Furthermore, because the wording of the requirements in this section does not

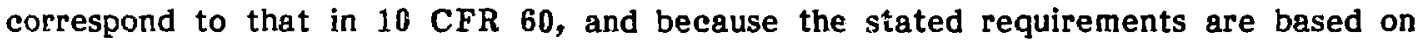
information in reports published in 1982, the equivalency of material in Sec. 3.1 and in 10 CFR 60 should be verified.

The U.S. Environmental Protection Agency (1982) published draft environmental standards for high-level wastes (proposed 40 CFR 191), which will be used by NRC in evaluating repository performance after permanent closure (10 CFR 60.112). Even though these standards have been modified and are not yet finalized, they are to influence final waste package design and are a portion of the regulatory requirements pertinent to the waste package program. Therefore, 40 CFR 191 should be discussed in Sec. 3.1, along with how these standards influenced the conceptual design and will influence subsequent aspects of the waste package program as presented in Sec. 7.

Several additional federal regulations are pertinent to waste package design because of the packaging, transporting, and handling activities that will take place during repository operation. While some of these regulations may ultimately be of more concern for repository design; many relate directly or indirectly to design considerations for components of the waste package. Many design requirements are mentioned in the report, but without reference to appropriate regulations. Regulations 10 CFR 20 (U.S. Nuclear Regulatory Commission, 1984b), 10 CFR 50 (U.S. Nuclear Regulatory Commission, 1984c), 10 CFR 71 (U.S. Nuclear Regulatory Commission, 1984d), 49 CFR 173 (U.S. Department of Transportation, 1984), and 30 CFR 57 (U.S. Mining Safety and Health Administration, 1982) should be briefly discussed in Sec. 3, and the role of each in guiding the waste package design should be briefly summarized if applicable to the 
content of the report. This discussion should be referencet appropriately in Sec. 7 to illustrate how proposed waste package program efforts relate to the specific regulatory requirements.

Sections 5 and 7 and App. F of the reviewed report also relate to regulatory requirements. Section 5 describes the performance of the waste package designs and relates their performance to the requirements and criteria presented in Sec. 3.1. However, the correspondence between the stated performance and a particular requirement or criterion is not always clear. This discussion would benefit from the addition of a few appropriately placed statements tying performance to a specific requirement. Furthermore, the stated performance should be related to specific sections of 10 CFR 60 and other regulations (e.g., 40 CFR 191 and 10 CFR 20) as appropriate. Similarly, the test program and verification activities described in Sec. 7 should reference appropriate regulations to illusirate how these activities will help to satisfy particular regulatory requirements.

Finally, App. F should be expanded to show how the existing content relates to 10 CFR 60 and other pertinent regulations. As presently written, it does not specifically refer to any pertinent published regulations. Readers would have to obtain the three referenced reports and compare them to published regulations to determine if the requirements are indeed addressed. A table should be added to show the correspondence between DOE, ONWI, and Westinghouse requirements and specifications and the appropriate regulations discussed in Secs. 3.1, 5, and 7.

In addition to 10 CFR 60, NRC has prepared several documents to guide DOE on repository licensing issues and procedures. Two such documents that relate directly to waste package performance and that are pertinent to the reviewed report are summarized below:

1. The U.S. Nuclear Regulatory Commission published a draf $\mathrm{t}$ technical position on waste package performance after repository closure (Cavis and Schweitzer, 1983), which presents the major issues and problems associated with evaluating whether a waste package complies with the performance objectives and the criteria and design requirements stipulated in 10 CFR 60 in general, and with those in Sec. 60.113 in particular. The document siates that several alternatives are available to address the performance criteria. In general, the objectives can be achieved by the whole waste package or by the individual components (i.e., waste form[s], container system, and packing). As stated in Davis and Schweitzer (1983, pp. 6-7), NRC's preferred approaches for ensuring compliance of a waste package with NRC criteria are, in decreasing order of acceptability:

a. Combinations of independent, high-integrity components which, by their individual behavior, can satisfy NRC criteria (redundant compliance). 
b. A single component which, by itself, can satisfy NRC criteria, in combination with other barriers that may not individually meet these criteria (single compliance).

c. Combinations of components that cooperatively comply with but individually do not completely satisfy proposed NRC criteria. These components acting together can be assigned, with some level of assurance, credit for complying with the performance objectives (composite compliance). A package constructed from these components should satisfy the 300- to 1000-year containment requirement.

Each of these options involves different considerations in terms of demonstrating reasonable assurance of the necessary compliance with the performance criteria.

Davis and Schweitzer (1983) also identify a number of major generic issues related to reducing the uncertainties in waste package performance after repository closure (i.e., issues that are independer: $s$ material and design choices and specific repository site conditions). These generic issues are (1) characterization of r:pository surface-water and groundwater attributes, including che ${ }^{-}$- stry and flow rates; (2) anticipated repository temperatures; (3) predictability of accelerated testing of waste package materials (i.e., mechanisms responsible for aging and estimated rates of degradation identified under accelerated conditions may not be applicable to normal stress conditions); (4) radiation effects; (5) total package testing, as opposed to testing individual components; (6) use of statistics to demonstrate compliance; and (7) use of modeling. Davis and Schweitzer's publication should be consulted for the details of each of these issues and the corresponding NRC positions.

2. The U.S. Nuclear Regulatory Commission also prepared a draft generic technical position on waste package reliability (U.S. Nuclear Regulatory Commission, 1984e) to provide guidance "for an acceptable nethod for demonstrating reasonable assurance that the waste package designs proposed by DOE will met the performance objectives and design criteria" contained in $10 \mathrm{CFR}$ 60. A major NRC concern in this regard is the uncertainty in data and models used to support a license application and how these uncertainties will be addressed, In assessing waste package performance, one method that is acceptable to the NRC staff is the use of reliability assessment techniques in combination with a fault-tree analysis (U.S. Nuclear Regulatory Commission, 1984e, p. 3). This approach is described and documented in the draft technical position, and the sections of $10 \mathrm{CFR} 60$ pertinent to waste gackage performance are appended. 
*Mr. Douglas F. Hambley

Geoscience and Engineering Group

Energy and Environmental Systems Division

Argonne National Laboratory

$\ddagger_{\text {Dr. Wyman Harrison }}$

Associate Director for Geoscience and Engineering

Energy and Environmental Systems Division

Argonne National Laboratory

*Ms. Amy B. Hull

Geoscience and Engineering Group

Energy and Environmental Systems Division

Argonne National Laboratory

Dr. Jerome Kruger

Department of Materials Science and Engineering

Johns Hopkins University

Baltimore, Maryland

Dr. Digby D. Macdonald

Chemistry Laboratory

SRI International

Menlo Park, California

$\S_{\text {Dr. Donald M. Rote }}$

Geoscience and Engineering Group

Energy and Environmental Systems Division

Argonne National Laboratory

Dr. James E. Russell

Texas A\&M University

College Station, Texas

Dr. Gary S. Was

Department of Nuclear Engineering

University of Michigan

Ann Arbor, Michigan

Dr. Bryan E. Wilde

Department of Metallurgy

Ohio State University

Columbus, Ohio

The credentials of the panel members are summarized in App. D.

* Member of core peer review staff.

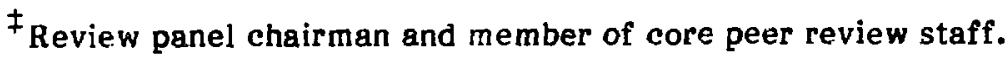

$\$_{\text {Review session chairman and member of core peer review staff. }}$ 


\section{Bryan E. Wilde}

Royal Institute of Chemistry, London: B.S. (1959)

Royal Institute of Chemistry, London: M.S. (1961)

Royal Institute of Chemistry, London: Ph.D., Physical Chemistry (1963)

Rennsalaer Polytechnical Institute: Ph.D., Materials Engineering (1965)

Dr. Wilde is Professor of Metallurgical Engineering and Director of the Fontana Corrosion Center at Ohio State University. From 1979 to 1984, he was Research Consultant and Section Supervisor, Corrosion Behavior and Failure Analysis Section, U.S. Steel Corporation Research. From 1968 to 1979, he supervised the Corrosion Kinetics Section of USS Research.

While at USS Research, Dr. Wilde developed electrochemical methods for previcting localized corrosion performance of materials. He supervised 26 seientists in analysis of environmentally and mechanically induced failures in materials and in the design of new materials. Dr. Wilde's recent research involves evaluating the corrosion performance of various materials, including aluminum, coated steel, and nickel; and characterizing the ravitation and erosion of materials, and the mechanisms of environmental crack ornwth under static and impact loading. He has also conducted research on hydrogen-inruced fracture of ferrous and nickel-base alloys.

Dr. Wilde is author of more than 65 publications deaiing with corrosion of materials and electrochemicel reactions under various environmental conditions. 
Both of these NRC documents state technical positions on evaluating waste package performance, which will obviously depend on the final design. Although the NRC positions are not binding and alternative approaches could be demonstrated, it seems prudent to consider these positions in preparing reference waste package conceptual designs. This admonition is particularly apt for Secs. 5 and 7 of the reviewed report. The package performance description (Sec. 5) and supporting material in the appendixes could be related to the major issues identified by Davis and Schweitzer (1983), and any uncertainties in the data and calculations should be at least qualitatively discussed. It may not be necessary to perform a complete reliability analysis for inclusion in the report; however, the docunentation provided to support the conceptual design is not adequate when judged against stated NRC positions. Similarly, the required development programs described in Sec. 7, especially in Sec. 7.2 .5 , should be reevaluated in t.arms of stated NRC positions on waste prckage performance to determine if the information necessary to adequately support a license application and to demonstrate reasonable assurance will be obtained. The results of this evaluation could be added as a separate subsection in Sec. 7 and summarized in the conclusions (Sec, 9).

In summary, the first stated conclusion of the report that "there is reasunable essurance that the design concept will satisfy all specified design requiremerts" (p. 133) has not been demonstrated, particularly in light of published NRC regulations and staff positions. 


\section{SUGGESTIONS TO IMPROVE PRESENTATION}

The overall readability of the report would be greatly improved if the following suggestions were implemented.

1. The report should be edited by a technical editor.

2. Consistent SI units should be used.

3. Jargon should be avoided.

4. Terms and acronyms should be clearly defined when first used, or a glossary of terms and a list of acronyms should be added.

In addition, the technical eredibility of the report is frequently undermined because assertions are made without supporting references. The report should be carefully reviewed with the purpose of providing supporting information and references where needed. The following more substantive comments are intended to assist the authors in revising the report to improve its understandability.

\subsection{INTRODUCTION}

The second paragraph of the introduction is difficult to follow. What is meant by an "additional conceptual design report"? Is this perhaps an "updated" report? What is the distinction between a "design activity" and a "preliminary design activity," and why is the distinction important? Were the geotechnical properties and repository parameters actually revised, or was new information obtained for these properties and parameters since the work that led to the earlier reference designs?

\subsection{PURPOSE AND SCOPE}

The introduction should include a section that explains the purpose of the report. As presently written, the introduction states only that the "report describes reference conceptual waste package designs," and that there are "reasons for issuing an additional conceptual design report." The scope of the raport shouid also be clarified. Section 2.3 merely recites the contents of the report. A statement of scope should address not only what the report covers, but should also explain why that coverage is of programmatic importance. More particularly, it should detail the limits of the topics to be covered and describe how such limits relate to program milestones or subsequent reports. 


\subsection{REFERENCE CONCEPTUAL DESIGNS}

It is not clear what a "reference conceptual design" is and what the term implies. Does it refer to a design that is fixed henceforth for the salt repository program? Or is it just the opposite? How is a reference conceptual design to be used? How is it different from any other sort of conceptual design, and what are the consequences of these differences? The authors must explain this terminology and its implications, preferably at the very beginning of the introduction.

\subsection{WASTE PACKAGE}

The term "waste package" should be clearly defined, not only in the introduction but also at the beginning of the exectitive summary. An accompanying sketch should show both elevation and plan views of the components of the entire conceptual waste package. Figure 1-1 (p. 6) shows only the overpack.

The authors should also consider using the terminology agreed to at the DOE Missior Plan Working Group Session of February 7, 1985. This terminology is explained in Stein (1985), as follows:

In general, high-level waste received at the repository will arrive in a ranister, either spent fuel consolidated inside a handling canister at the MRS [monitored retrievable storage] or processed high-level waste (either defense or commercial) inside a process canister. The metal barrier placei around this canister to meet the 10 CFR 60 requirements [in particular, the containment performance objective of 60.113(a)(1)(ii)(A)] will be called the disposal container. The previously used term "overpack" should only be used in the context of an additional barrier needed to repair a defective container, or as a verb, such as "overpacking" canistered waste with a container or "overpacking" the alternative salt container with a thin layer of Ticode-12 alloy. The program will also continue to use the term packing for the crushed host rock or rock and other material (such as bentonite) mixtures placed between the container and host rock wall of the emplacement hole.

The above terminology may require NRC concurrence before it is adopted by DOE. The authors should track the evolution of this DOE-preferred terminology.

\subsection{PROPRIETARY COMPUTER CODES}

The repository thermal code WECAN (Westinghouse Computer Analysis Program) is mentioned in the text and in App. D, but no reference is given. Appendix $D$ briefly describes relevant parts of the code, but no information is given as to its availability. All codes used for performanee assessment in the Civilian Radioactive Waste Management Program must be available to the public. The text should explicitly address whether the WECAN code is proprietary. 


\subsection{CONSISTENCY OF DESIGN CRITERIA}

The report must be internally consistent with respect to design criteria. Contradictions such as the following must be resolved. On page 163, the failure of the overpack through localized corrosion is considered improbable. Then, on page 18J, the report states: "since local corrosion is regarded as the most likely mode of package failure ...." Such inconsistencies tend to undermine the technical validity of the report.

Similarly, it is not clear what constitutes "failure." For example, on page 34, "failure" is defined as $a$ "breach of the overpack." Buckling of the overpack is not regarded as a "failure," even though it would make the method of retrieval preferred in the report difficult or impossible. Such "failure" might also generate tensile stresses at or near the head weldments, leading to stress corrosion cracking. Buckling could also damage the waste canister and form.

On page 35 , the design assumes unlimited anoxic brine availability, whereas the suitability of carbon steel from a corrosion standpoint is justified not only on the basis of a "limited" supply of brine (p. 39), but also on the assumption that any brine present will be used up. The "limited" supply of brine is, in fact, the basis for dismissing a number ot degradation processes, including radiolysis and waste form leaching. It is never clearly explained why the "expected repository condition" of limited brine $(\sim 30 \mathrm{~L})$ is the only one needing consideration.

\subsection{TEST PROGRAM}

Many assumptions are made in the main text and in the appendixes, and it is difficult to be sure whether the proposed tests cover all of the assumptions that are not adequately substantiated. A table should be added that lists all assumptions and gives their status with respect to short-and long-term testing and verification. 


\section{TECHNICAL CONSIDRRATIONS}

Section 4 discusses in some detail the technical issues judged to be of major importance. Brief technical comments, questions, and editorial suggestions are covered in Sec. 6.

\subsection{MATERIALS SELECTION}

Materials selection is of paramount importance in the design of waste packages. Given the sensitive sociopolitical nature of radioactive waste disposal, a fail-safe criterion should rank above all other considerations, including cost effectiveness. Considerations like the strategic or salvage value of materials seem almost irrelevant by comparison.

\subsubsection{Overpack Materiais}

The authors of the report seemed determined to justify a previous choice of low carbon steel as the overpack material. Aithough they argue that the chosen overpack material, with an appropriate thickness allowance for corrosion protection and structural strength, would meet regulatory requirements, much of the evidence presented to suppo't their choice is based on material cost, availability, fabricability, and weldability -- all of which are basically cost considerations.

Cost effectiveness criteria should not have the same priority as a fail-safe criterion. Likewise, although a worthy objective, the question of "depleting supplies of critical strategic materials" should not influence the choice of overpack materials. Also, ease of production and fabrication should be considered in the final design but should not dictate the generic nature of the material used. For example, the authors mention the weldability of carbon steel compared to higher alloys as cne of its favorable attributes as an overpack material, yet the U.S. Navy has been welding high-nickel alloys for fail-safe submarine operation for years.

The discussion of the choice of carbon steel as the overpack material (p. 31) is not only unconvincing as to its technical validity but is also premature. The authors seem to "like" carbon steel because it can be cast and welded, which are not unique attributes. Alternative fabrication methods for enhanced quality (e.g., seamless piercing, extrusion, and forging) are not discussed. Likewise, the uncontrolled hardness of the heat-affected zone associated with a thick section weld in a carbon steel of the type being considered is not addressed. This omission could be the "Achilles' heel" of the design. The technieal review procedure would be assisted if the anticipated heataffected-zone hardness maximum could be included with the physical properties in Table 3-4 to obtain some feel for the possibilities of stress corrosion cracking or hydrogen embrittlement.

For design purposes, the criteria that constitute a "failure" must be unambiguously identified. On page 34, "failure" is defined as a "breach of the 
overpack." This circumstance is later rationalized as unimportant because of limited availability of brine and formation of gel-like corrosion products with glass. Another example of "sliding" criteria occurs on page 36, where the design assumes unlimited anoxic brine availability, whereas arguments for the suitability of carbon steel with regard to corrosion are based on a "limited" supply of brine (p. 39), implying that all the brine will be used up.

With respect to Secs. 5.1-5.3, a problem associated with long-term thermal performance that is not addressed is the long-term phase stability of carbon steel at high temperatures. The effects of long-term aging on mechanical properties of various alloys are worthy of recognition.

On page 166, the selection of carbon steel is justified by reviewing previous consideration of other alloys, including high-alloy skins. Nickel and titanium alloys were found to be superior to carbon steel, but the authors go on to state that carbon steels can be used in greater thicknesses. Again, the authors seem convinced that corrosive attack will be by general corrosion. They fail to mention that nickel and titanium alloys are superior in general corrosion resistance to carbon steel and are also immune to stress corrosion cracking and possibly to hydrogen embrittlement. An alterriative should be available if carbon steel proves a poor choice.

With regard to the long-term corrosion program discussed in Sec. 7.2.2, the purpose of "verifying" the material chosen for fabrication for up to 20 years after it has been used for fabrication is not clear. What if it is found that after 20 years the wrong material has been used. What options are then available?

The following comments relate to the selection criteria discussed in App. G, several of which are of questionable validity.

1. Avoiding creating an underground deposit that may be valuable in the future must de secondary to choosing a material that will do the job.

2. Avoiding depleting strategic materials and avoiding the costs of an expensive research and development program should not be given undue emphasis in materials decisions.

3. If performance experience had been considered, Hastelloy C276 or Ticode 12 might have been chosen as the reference material.

4. Production and fabrication factors considered should include cladding, co-piercing, and forging. Casting has relatively high rates of rejection based on quality control measures.

5. Final selection ariteria for a reference material for a sociopolitically sensitive project such as radloactive waste disposal should be of a fail-safe character, with cost constraints being much less important. 
6. On page 240 , the last sentence implies that nickel alloys are more difficult to fabricate than less corrosion resistant alloys, which is not true. Autogenous welding of Inconel 600 and 625, as well as Hastelloy C276, is done routinely with well-established procedures for the U.S. Navy in its nuclear propulsion program.

7. On page 241, castability is incorrectly included as a major factor in waste package materials selection.

8. On page 242 , carbon steel appears to have been selected on the basis of the deleterious effects of alloying elements on welding. This argument does not make sense in view of the ease with which face-certered cubic materials, such as Type 304, Hastelloy C276, and Inconel 600 , can be welded.

9. Selection of carbon steel as the overpack material was based on faulty reasoning. Because of some serious deficiencies (e.g., susceptibility to localized corrosion), carbon steel should not have been considered a reference material candidate.

10. Using a lining or cladding of corrosion-resistant material over a structural base of carbon steel is the most sensible and defendable concept proposed. However, it is rejected promptly on the basis of cost, using data such as those presented in Table G-2. Cost comparisons based on cost per unit weight of metal are of questionable value and may be in error.

\subsubsection{Waste Form Canister Materials}

Selecting materials for the waste canisters is scarcely discussed. Even the design requirements are not given in detail. Although the overpack is designe $\mathrm{I}$ to contain the waste for the first 1000 years, the possible additional protection that could be afforded by a well-designed waste form canister should not be ignored. If adequate importance were given to the canister, it need not be assumed that leakage would occur in the event the overpack failed. For example, why is stainless steel used for the canister material? It is susceptible to pitting in salt solutions, whereas the more expensive Inconel 600 is not. The two alloys are about equal in formability.

\subsection{CORROSION ANALYSIS}

The corrosion analyses presented are inadequate to support the contention that carbor steel is a suitable material for the canister overpack. Numerous assertions are made, but they are either poorly supported or totally unsupported by appropriate literature citations. Great emphasis is placed on the importance of general corrosion, but the authors fail to properly characterize the factors influencing it. Relevant publications appear to have been ignored. 
Localized forms of corrosion, with the exception of pitting, are wrongly dismissed as unimportant. The assumption that the pitting corrosion depth would be less than or equal to two times the general corrosion depth is never adequately iupported. Furthermore, the pitting analysis is inadequate in that it is not based on well-established statistical principles. In addition, the effects of radiation are unjustifiably downplayed.

Although it is noted that only "expected repository conditions" (namely, very limited water) need be considered, the authors acknowledge the need to account for the uriexpected availability of unlinited water. However, they consider this possibility only with respect to general corrosion of the overpack, and not to localized corrosion, leaching, and radionuclide transport.

\subsubsection{General Corrosion}

The factors influencing general corrosion are not adequately characterized. Such factors include carbon content, alloying and impurity concentrations, microstructure discontinuities, exposure history, and radiation effects. If these factors are considered unimportant, or if the design corrosion rate was chosen to compensate for such factors, then something should have been said and supporting references given.

An Eh-pH diagram for iron at high temperatures is not given. If the relationships are strongly temperature dependent, then conclusions should not be drawn from a diagram for $25^{\circ} \mathrm{C}$ when waste package surface temperatures are expected to be considerably higher. Furthermore, the analysis seems to contradict the information summarized in Fig. B-1. The authors' projected $\mathrm{pH}$ and Eh numbers, 5-8 and $\mathbf{- 0 . 2 1}$ to -0.23 , respectively, place iron in the corrosion region of its Eh-pH space, not in the passive region. On the basis of this diagram, iron should not be "the metal of ehoice for waste p-ckages in salt." In addition, the cited work does not include radiolysis effects.

The effects of chloride ion concentration on stability zones are not addressed. In fact, the extensive literature on the corrosion of iron and carbon steel in chloride (and other salt) solutions at elevated temperatures has apparently boen ignored. Many of these studies sought to define the corrosion behavior of carbon steel in steam generator crevice environments in pressurized water reactors in an effort to understand denting corrosion. Many of these studies have shown that under certain conditions the corrosion of carbon steel exhibits a linear rate law or even autocatalytic behavior in hightemperature $\left(250^{\circ} \mathrm{C}\right)$ concentrated $\mathrm{NaCl}$ solutions. Under these conditions, extremely high corrosion rates are observed, with penetration rates exceeding several centimeters per year.

The corrosion product formed is a highly crystalline and porous magnetite that offers little protection to the underlying steel. Indeed, this porous film aggravates the corrosion problem, because it allows for spatial separation of the anodic and cathodic reactions, thereby leading to formation of a much more aggressive solution within the pores. Previous work has shown that this type of attack will oceur under anoxic conditions, provided that the $\mathrm{pH}$ is sufficiently low or that reducible cations are present in the solution. The fact that acidic environments may rorm as the result of gammaradiolysis of nitrogen-contaminated brine should be sufficient reason to explore in detail 
the possibility of accelerated attack on carbon steel. A Ph.D. thesis by Park (1983) on this subject lists many pertinent references.

The equations listed in Sec. B.3.3.1 do not necessarily describe "stoichiometric corrosion requirements" but rather one chemical pathway. The partial transformation of iron to $\mathrm{Fe}^{++}$still constitutes corrosion and, in this case, the anoxic:oxic water requirement is $2: 1$, not $4: 1$. This analysis also ignores the effect of radiolysis.

\subsubsection{Localized Corrosion}

On the basis of the expected linited availability of water, the evaluation of local corrosion (other than pitting) is limited to general corrosion attack of the upper and lower heads. Two general comments are in order here. First, could even more localized corrosion occur? Second, arguments supporting the limited extent of corrosion based on a limited amount of brine do not mean anything if the major form of "failure" is localized (e.g., hydrugen embrittlement or stress corrosion cracking). A classic example of this phenomenon is the failure by hydrogen embrittlement of high-strength steels and other high-strength alloys in water-contaminated benzene, in which water has very limited solubility. Thus, demonstration of a limited-amount-of-brine situation does not necessarily preclude premature failure of the overpack by hydrogen embrittlement or stress corrosion cracking.

The corrosion allowance approsch (p. 40) is therefore valid only if general corrosion is the majo: form of attack. In the absence of evidence to the contrary, it would appear that general corrosion is the least likely form of overpack "failure," the most likely being hydrogen embrittlement of the welded head due to radiolytically generated hydrogen, stress corrosion cracking at uncontrolled hard zones in the weld heat-affected zone, and stress corrosion cracking due to $\mathrm{NO}_{3}{ }^{-}$eracking from radiolytic effects on trapped nitrogen (air).

Stress Corrosion Cracking. The nature of the stresses expected in a repository is scarcely discussed in the report. The notion that all stresses will be "essentially compressive" may be valid, but it is not supported by references. The stresses are likely to be nonuniform and may contain tensile as well as compressive components. The residual closure stresses are not expected to be uniform around the weldment. Also, the effect of deformation on the stress field is not addressed.

The assumption that carbon steels do not suffer stress corrosion cracking in hightemperature aqueous solutions is incorrect. For example, Choi et al. (1982) show that carbon steel cracks in pure water at high temperature under very mildly oxidizing conditions. Numercus other studies of this type have been carried out under the sponsorship of the Electric Power Research Institute. These studies should be reviewed before any final decisions are made with respect to the corrosion and stress-corrosioncracking behavior of carbon steels in high-temperature brine environments.

On page 177, the authors state that chloride-induced stress corrosion cracking is not typically encountered in unalloyed carbon steel, which is true for annealed materials. If, however, weldments contain a heat-affected zone with Rockwell " $\mathrm{C}$ " hardnesses 
greater than 28, stress corrosion cracking will occur in seawater at ambient temperature. Also, it would be wrong to imagine that "high" concentrations of $\mathrm{NO}_{3}{ }^{-}$are required for stress corrosion cracking to occur. It has occurred in X-52 linepipe steel ( 0.3\% carbon, $0.8 \%$ manganese) in $100 \mathrm{ppm} \mathrm{NO}_{3}{ }^{-}$at room temperature after 8-12 months of being stressed as U-bends.

The question of "small flaws" in the welds (p. 48) is also relevant here. The report states that small flaws undetectable by magnetic particle testing (MT) are not expected to provide sites for accelerated corrosion penetration under expected corrosion conditions. This assertion needs to be supported because such flaws are usually good sites for initiation of stress corrosion cracking.

Pitting Corrosion. Pitting corrosion is not unambiguously defined in the report. The assumption that pit depths will be only twice the general corrosion loss is not adequately supported. In the first place, it is based entirely on data obtained for corrosion occurring at temperatures considerably below those expected to obtain in a salt repository. In the second place, since pitting attack can only be described in terms of some appropriate distribution function (e.g., Weibull), pit depth cannot be analyzed in the manner presented. Instead, probabilities must be assigned to various pit depths, and the total thickness of the carbon steel overpaci must be assigned such that a negligible probability exists that an individual pit will exceed that dimension during the exposure period of interest. Again, the authors appear unaware of the literature pertaining to this subject. The pertinent literature should be examined to develop a more realistic analysis of pitting corrosion.

The effect of radiolytic oxidizers on pitting also needs careful examination. Indeed, the whole question of a critical pitting potential is usually ignored by designers of overpacks. Radiolytic oxidizers might raise the potential of the overpack above its critical potential for pitting, which would initiate severe pitting. Therefore, it is necessary to determine whether the concept of a critical pitting potential is applicable to steel overpacks in a salt environment. If it is, a tool is available for ensuring that pitting will not occur as long as conditions are maintained below the pitting potential. The discussion on page $\mathbf{1 2 1}$ of effective determination of the Eh of brine is related to the issue of a critinal pitting potential. The Eh value of brine under repository conditions needs to be determined. If it can, it will be possible to ascertain whether the overpack is above or below the critical pitting potential.

Other Chemical Species. It is important to evaluate the roles of chemical species anticipated to be important in a salt repository. Such species include $\mathrm{H}_{2} \mathrm{~S}, \mathrm{NO}_{2}$, $\mathrm{H}_{2}$, and $\mathrm{MgCl}_{2}$. For example, formation of $\mathrm{NO}_{3}^{-}$from $\mathrm{NO}_{2}$ could result in the wellknown stress corrosion of steel in hot nitrate solutions. The stress would be provided by the lithostatic pressure. Also, in contradiction to the assertion on page 163 that too little hydrogen would be present in the system to cause hydrogen embrittlement, it must be kept in mind that not much is needed. Finally, if $\mathrm{H}_{2} \mathrm{~S}$-containing brines are a possibility, then sulfide-induced fracture of the welded end cap on the overpack is a potential problem that has not been addressed. 
Radiation Effects. The influence of radiation on corrosion rates can be twofold: (1) effects on the kinetics of the two electrochemical partial processes and (2) production of species from the environment that subsequently degrade the overpack (e.g., production of nascent hydrogen and $\mathrm{NO}_{3}{ }^{-}$). Hydrogen would be readily absorbed by the steel and could mechanically degrade the heat-affected zone of the weldments, leading to fracture. Nitrate produced from trapped air could lead to stress corrosion cracking.

The general conclusion that gamma- and neutron-radiolysis of brine are likely to have only a negligible effect on the corrosion of carbon steel in the repository environment is not sufficiently supported by experimental data. A considerable body of data exists in the literature on the chemistry of irradiated brines, and various highly corrosive species have formed under steady stata conditions. These species will shift the redox potential in the positive direction, which may lead to an increased general corrosion rate or to a significantly accelerated rate of pitting.

\subsubsection{Data Extrapolation}

Extrapolation of the corrosion data obtained from the testing program to 1000 years is not addressed. A method for this purpose must be developed and tested over as long a period as possible, using either long-term test data or suitable analogs. This approach supports extending the long-term testing program as much as possible, and certainly for as long as the planned retrieval period. It also supports selecting a retrieval option that includes removal of the entire waste package so that overpacks can be inspected for corrosion demage.

\subsubsection{Corrosion Allowance}

The procedures described in App. B for calculating the corrosion allowance of the steel overpack are suspect. First, the temperature-dependent corrosion rates (Egs. 12 and 13) are based on data for a period of one year; in only one case are there enough data (more than one point per material) to establish a temperature dependence. Therefore, Eq. 12 is totally without foundation.

Second, it is assumed that the corrosion rate remains constant, unaffected by the buildup of corrosion products. If buildup does occur, it is assumed that the rate would decrease. However, if corrosion is occurring in the antive region of the Eh-pH diagram, then a decrease in the corrosion rate would not occur. From the data given on page 145, this situation is a distinet possibility.

Third, the long-term test results are based on data taken over a 16-year period on cast steels. Are these data relevant to type 1018 steel? Also, the condition of the material has a strong effect on both general and pitting penetration rates. Neither the composition nor the condition of the material is accounted for in Eq. 18.

Fourth, Eq. 18 is developed for oxic tropical seawater (pa 174). The justification for using the seawater analog is not satisfactory. To relute the seawater analog to the ancxic corrosion rate, a factor of 6.9 is used. To introduce a temperature dependence, 
the three data points for type 1018 steel are used. Hence, Eq. 21, which is supposed to apply to type 1018 steel at $100-250^{\circ} \mathrm{C}$ in an anoxic brine environment, is based on 16year corrosion data (presumably at $25^{\circ} \mathrm{C}$ ) in oxic seawater for cast steels. The temperatur : dependence is borrowed from a relation for steel in oxic conditions based on one data point. The resulting equation is then adjusted for anoxic conditions using a factor of 6.9 determined from the same data as the temperature dependence. Finally, a pitting fretor of 2.0 is used to roughly approximate some highly varying data (Figs. B-5 and $\mathrm{B}-6)$.

This procedure does not provide reasonable assurance that Eg. 21 is applicable to the problem at hand. Calculating total corrosion relies on using the appropriate corrosion rate equation for the time interval during which a given temperature prevails and summing the values over all time intervals. However, these equations are based on isothermal tests with an identical starting material; possible history-dependent effects are not accounted for.

\subsubsection{Testing and Verification Program}

The following modifications are suggested for the short-term testing program and the long-term verification program.

1. Materials other than carbon steel should be included (e.g., titanium alloys, Hastelloy C276, and other potential cladding alloys, weldments, etc.).

2. The statement that $10-20$ years of solid data will greatly reduce the error band in the extrapolation to 1000 years is true with respect to present data. The verification procram should be extended over the entire retrievability period to provide a much better indication of long-term performance.

3. The relevance of data obtained in tropical seawater of lower ionic strength than that prevalent in brine should be explored. The stability caused by the complexing of protective films and the nature of deposited films of corrosion products are a strong function of ionic strength (e.g., as typified by the performance of weathered steels).

4. Tests should be conducted to relate the microstructure of the steel at and away from the welds to localized and galvanic corrosion processes.

5. Additional emphasis should be placed on the problems of pitting, crevice corrosion, stress corrosion cracking, and hydrogen embrittlement, as well as on the role of verious chemical species other than $\mathrm{NaCl}$. 
6. Further work is needed on the effects of radiation on corrosion kinetics, on protective films, and on production of species that might degrade the overpack or waste form.

7. A properly based statistical analysis of pitting attack is essential, especially because the overpack is most likely to be penetrated first by this form of corrosion.

8. More emphasis should be placed on linear and autocatalytic corrosion of carbon steel in high-temperature brines, since these forms of attack are known to lead to extremely high corrosion rates.

9. The effect of radiolytic oxidizers on pitting should be examined carefully, as should the applicability of the concept of a critical pitting potential to steel overpacks.

10. A test matrix is needed for a reference temperature of about $250^{\circ} \mathrm{C}$. All variables should be checked to ensure that they do not influence processes differently at high versus low temperature. In other words, the independence of the variables with respect to temperature should be tested.

11. A procedure to extrapolate test results to 1000 years should be developed and tested over the duration of the verification program and also tested against other long-term test or analog data.

\subsection{BRINE MIGRATION AND THE LOCAL ENVIRONMENT}

The discussion of brine migration and related matters is poorly referenced and out of date. The most recent reference is 1981. Much work was done in this area between 1981 and 1984, the year the report was released.

\subsubsection{Assumptions}

Several important assumptions in the report are inadequately discussed or referenced. In Sec. 5.2, for example, the effect of radiolysis on corrosion products and leach rates is not considered. The extensive work on how radiolysis affects salt and brines is totally ignored. The chemical products of radiolysis are ignored, except in the section specifically dealing with radiolysis. Also, it is assumed incorrectly throughout the report that the gaseous phase is pure water vapor, rather than a mixture that could contain such gases as $\mathrm{H}_{2}, \mathrm{O}_{2}, \mathrm{H}_{2} \mathrm{O}_{2}, \mathrm{CH}_{4}, \mathrm{CO}_{2}, \mathrm{H}_{2} \mathrm{~S}$, and $\mathrm{HCl}$. Also, it is not clear to what extent the assumptions of $30 \%$ porosity of the backfill and anoxic brine conditions are compatible. 
In Sec. 7.1, further optimistic and unsubstantiated assumptions are made about corrosion nntential and brine migration. Unly two migration mechanisms are considered operative, both of which are oversimpilfied. $l$ : is also erroneous to assume that transport is independent of pressure.

Although it is commendable that App. B includes a discussion of the anoxic rock salt environment, some ather fallacious assumptions are made. For example, the neutrality of the salt rock environment has not been confirmed, and it may be wrong to implicitly assume that radiolysis has no significant effect. Also, hydrous minerals such as clays, polyhalite, and gypsum cannot ie entirely "avoided as a matter of course." Finally, at the thermal upper limit of $250^{\circ} \mathrm{C}$, hydrated mineral decrepitation is a distinct possibility.

Selection of $30 \mathrm{~L}$ as the upper limit on the quantity of brine is never adequately supported or referenced. This limit, which is apparently based solely on liquid brine inclusions, does not give consideration to other scurces of water, including hydrated minerals and hygroscopic water absorbed by the excavated surfaces of the repository and the backtill.

\subsubsection{Models}

The migration models reviewed in the report were state of the art in 1980 . However, the report totally ignores gas-liquid fluid inclusions, which migrate away from the heat source (waste package) and have the potential to disperse radionuclides. Published information and modeling results about the stress-gradient mechanism for brine migration were also ignored.

Because the two mechanisms discussed (liquid brine inclusion motion and vaporphase transport) are modeled in an oversimplified manner, the value of the modeling results is questionable. The modeling is essentially an oversimplification of some of Jenk's (1979) earliest work; in the original papers, the models are properly documented, verified, and validated. Finally, laboratory studies of intragranular diffusion cannot be safely extrapolated to massive rock conditions, and hydrated minerals are not considered as a water source in the models used.

\subsubsection{Data Needs and Testing Program}

The Eh-pH regime expected in the emplacement area needs to be studied experimentally. Fundamental corrosion studies are also needed. The report does make a point of stressing areas where more data are needed to conduct proper design analyses. However, the notion that "there is a good chanee that radiation effects need not be simulated as is planned for some of the Asse emplacements" indicates an unsubstantiated bias on the authors' part. Clearly, the real situation should be simulated as closely as possible, especially in light of the confusion with regard to interpreting the results of brine migration tests. Furthermore, radiation is a reliable way to provide a heat source for the brine migration experiments. 


\subsection{LEACHING}

A basic assumption made in the report when discussing waste form leaching is thet there will be an "expected lack of fluids to effect leaching." This assumption is based on studies of brine migration that were limited to water-vapor and fluid-inclusion migration models under anoxic conditions. Even if the basic stoichiometric premises are correct, the assumption is overly optimistic and does not correspond to a worst possible case.

Other assumptions in Sec. $\mathbf{5 . 2}$ concern corrosion processes. Essentially, it is the authors' contention that corrosion products are "stable, insoluble, [and] inert to the designated waste form." Such assumptions for a salt repository must be viewed with considerable skepticism. Evidence must be provided regarding leaching rates over the full range of expected site-specific repository conditions.

The test matrix for leaching studies is so poorly defined that the objectives of the proposed testing program are unclear. It is wrong to assume that tests under oxic conditions can cubstitute for tests of the effects of radiolysis. The reason for choosing stagnant conditions for flow is also unclear. Finally, the proposed test program does not address known inadequacies of the data base concerning the long-term stability and leaching properties of Zircaloy-clad fuel rods.

\subsection{THERMAL AND STRUCTURAL ANALYSIS}

In general, the assumptions made in the thermal and structural analyses either are not stated or are vaguely stated. For example, the decay characteristics for commercial high-level waste are given without a source or a description of the assumptions made in their development. However, most of the important factors influencing the thermal history of the waste package appear to have been considered, although in a somewhat cursory way. Parameter studies appear not to have been done, and certain issues have not been addressed, such as how the thermal response would change if the backfill were saturated by inflowing brine.

All of the available data and information sources have not been used. In fact, the authors seem unaware that full-scale electrical heater tests were conducted at the Avery Isiand mine and that the question of the pressure loading on the overpack has been previously addressed.

It is difficult to determine whether the analyses are correctly interpreted because so few details are given. However, the authors seem unaware of the influence that the properties of the rocks in the geologic column and the values assumed for the surface temperature and geothermal flux have on temperatures at the burial horizon. Further, the text does not mention that these values are site specific.

Many of the important inadequacies in the data and analysis are identified. Section 7, for example, suggests that numerical models be constructed to study certain aspects, such as the pressure on the overpack. In general, however, the authors do not acknowledge previous studies and underestimate the complexity of the mechanical 
behavior of salt. For example, the thermal expansivity of salt cannot be adequately modeled by a simple coefficient of thermal expansion. Finally, given the current state of knowledge, the treatment of heat transfer in consolidated spent fuel is unnecessarily simplified.

\subsubsection{Thermal Analysis}

In Sec. 5.1.1 transient-analysis interface temperatures are used as boundary conditions in steady state models without any discussion of the applicability of this approach. Also, several limits on temperature, areal thermal loading, etc., are used throughout this section without referring to Table 3-3. No source is given for the reference repository characteristics given in Table 3-3; the text simply attributes these characteristics to ONWI (p. 26). The "depth below surface" is given as TBD (to be determined). However, temperatures at the burial horizon do depend on depth, the geothermal flux, and the assumed surface temperature, as vaguely discussed in App. D ( $p$. 204). This dependency may be significant when calculated temperatures approach their limits; for example, the maximum salt temperature for the commercial-high-level-waste case reaches $230^{\circ} \mathrm{C}$, whereas the maximim allowable temperature is $250^{\circ} \mathrm{C}$. No parameter study results are presented to help put the situation in perspective. In fact, the possibility that the temperatures calculated may not be representative of all potential salt repository sites is not mentioned.

The Westinghouse Computer Analysis Program (WECAN) is mentioned, but no information is given as to documentation, verification, or validation. It is not clear whether this code is in the public domain.

The report states that "peak rowk temperatures from the model agree with calculations for both salt and basalt reported by Claiborne et al. (1980)." Because the thermal properties, waste decay rate, and ambient temperature for salt were all different in Claiborne e $\hat{i}$ al. (1980), any agreement in peak temperatures appears to be fortuitous and thus of no particular significance. The comparison with basalt seems to be irrelevant.

The treatment of the consolidated spent fuel waste forms raises a number of issues. First, fuel rod properties are not completely characterized. Detailed characterization data on fuel rod batches as a function of reactor identity are given in Science Applications, Inc. (1980). Although the number of reactors is very limited, the data base is very detailed. While the assumption that earlier ree tor designs used smaller arrays is generally valid, it is probably not valid to assume that rod dimensions are constant over time for a given array size.

Radiation is assumed to be not only the primary but also the sole mode of heat transfer in a close-packed array of fuel rods. In analyzing heat transfer between fuel and cladding during reactor operation, heat transfer across the gap between the fuel and the cladding is usually modeled as occurring by conduction and convection. Typical gaps are 0.05-0.10 $\mathrm{mm}$, and operating temperatures are probably higher than those in the canister. Therefore, although a radiation-only heat transfer mechanism may be conservative in light of what is known, such conservativeness is not needed. This 
calculation will be complicated if ratchetting of the clad due to mechanical interaction between the pellets and the cladding is considered. Because localized deformation occurs in the reactor as a result of such interaction, it is unreasonable to expect rods to touch line to line.

\subsubsection{Initial and Boundary Conditions}

The initial temperature at the burial horizon is given as $34^{\circ} \mathrm{C}$. However, although a geothermal flux is mentioned, ine value used in the calculation is not given. Further, it is impossible to establish the initial temperature without stating the depth. (From Fig. D-1, the depth used was apparently $600 \mathrm{~m}$.) Also, it is well known that the temperature profile depends on the thermal properties of each of the lithologies in the stratigraphic section. This dependence holds true particularly in the case of sections including significant fractions of salt because of its relatively high thermal conductivity. No thermal properties are given for the other rocks in the column. Note that the initial temperature at $610 \mathrm{~m}$ used in Claiborne et al. (1980) is about $25^{\circ} \mathrm{C}$ compared with $34^{\circ} \mathrm{C}$ in the report.

\subsubsection{Repository Material Properties}

Table D-1 gives the material properties used in the repository mcdel; however, no source is given for these properties, and they are not the same as in Claiborne et al. (1980). This is bound to be confusing when the abstract states that the report provides conceptual designs to "baseline."

\subsubsection{Structural Performance}

In Sec. 5.1.3, the term "structural capability" is used without definition. The authors state that the stiuctural capability of the overpack material is not temperature dependent at temperatures below $150^{\circ} \mathrm{C}$. While this statement is probably true, it should be referenced to an appendix or a source. The last sentence on page 66 notes that the "structural design basis does not require consideration of thermally-induced structural capability degradation for the heads until the material temperature reaches $370^{\circ} \mathrm{C} . "$ However, no reference is given for the structural design basis.

The American Society of Mechanical Engineers' Boiler and Pressure Vessel Code may be conservative for its intended use, but it may not be conservative for the time frame and corrosive environment of a repository in salt.

\subsubsection{Thermal Expansion of Salt and Effects of Creep on Waste Packages}

In Sec. 7.1.5, the report mentions analytical evidence that ambient lithostatic pressure may be increased by local, transient, and thermally induced pressures due to heating of the salt. Even in the absence of heating, the emplacement holes are in a zone where the stresses are increased because of the stress concentration around the 
excavated room. The pressure to be expected on the overpack has been studied, but nothing has been proved conclusively. The studies indicate that high pressure is to be expected on the overpack because of thermal expansion of the salt. Further, recent: laboratory tests on salt from the Avery Island mine indicate that salt under confining pressure may initially decrease in volume as its temperature is increased and then increase in volume after a volumetric strain approximately equal to the porosity is reached. The assumption of a constant coefficient of thermal expansion for salt may therefore be inadequate. A further complication is selecting the appropriate modulus of elasticity to use in the calculations. First, salt does not generally behave elastically. Thus, using elastic moduli in the numerical analysis is necessarily an approximation. Second, the moduli commonly reported are unloading moduli, which are considerably higher than those obtained under loading conditions.

The report should be revised tc reflect that (1) field test data pertaining to the thermal expansion of salt are available, although for shallower depths than expected for a repository; (2) related analytical studies have been made; and (3) any new study in this area should build on but not duplicate the previous work.

The report states that "while it is known that salt creeps more rapidly as its temperature increases, this effect has not been quantified on a repository basis." Project Salt Vault results indicate that the salt creep rate does increase significantly as the temperature increases.

On page 115, under "Maximum Load on Waste Package," the report mentions the thermal expension coefficient and Young's Modulus of salt as functions of temperature. The "ultimate compressive and shear strengths of the salt" have little meaning because of the significant strain-rate sensitivity of the salt. Jaboratory test results indicate that salt begins to flow upon the application of virtually any deviatoric stress. The observed strain rates are higher at higher temperatures and deviatoric stresses.

\subsection{RETRIEVABILITY}

In Sec. 3.6.1, the report states without justification that "recovery of just the waste form, in its canister, is assurrad to be the most probable retrieval method." No alternatives are mentioned. However, in Sec. 5.3, two alternatives are presented: overcoring and retrieving the entire waste package and retrieving the canister and waste form only. The arguments presented to eliminate overcoring as a plausible alternative are unconvincing. If the pintle is corroded, it will interfere only with the method involving removal of the canister and waste form only. With overcoring, at least as proposed for the Waste Isolation Pilot Plant (Steinbaugh, 1979), the pintle is not used in the retrieval operation. Furthermore, if the pintle is corroded, the threads joining it to the container are also likely to be corroded such that the pintle is fixed in place. If so, how can the pintle be removed so that the hole can be used to attach the cutting machine? In addition, using the hole would require the cutter and the container to be in perfect alignment. Such perfect alignment would be extremely difficult to achieve if the machine were to be operated by remote control (p. 75). In short, the proposed retrieval method has not been thought through carefully. 
From the description in the repc't, it appears that cutting of the container head, discussed above, and canister removal will be performed by two different machines and that the waste canister will be exposed between operations. It is highly unlikely that NRC would find this practice acceptable. In addition, a casing would be required to ensure that the hole would not cave in before retrievai was completed. In summary, the proposed method is not well conceived. It seems to present more difficulties than the overcoring alternative.

Finally, one of the important reasons for requiring that the entire waste package be retrievable was presumably to inspect it for corrosion damage. If only the waste form and canister are retrieved, this valuable verification procedure is lost. 


\section{U.S. DEPARTMPNT OF ENERGY REVTEW QUESTIONS}

In his letter to Argonne requesting peer review of the Westinghouse report (see App. A), R.B. Lahoti requested that answers to seven questions be included in the review report. Those seven questions, together with the answers, are presented below:

1. Are the necessary assumptions described reasonable, and have they been verified for applicability?

Many of the assumptions are clearly stated and seem reasonable. However, questionable assumptions and assertions (i.e., statements not explicitly designated as assumptions) are made with regard to materials selection, corrosion attack, brine migration, availability of water, importance of radiation, and procedures for calculating the corrosion allowance. In general, they are either poorly supported or totally unsupported by acceptable arguments in the report or by literature citations.

\section{Are design methods appropriate?}

Models are used to calculate brine migration. The application of these models (not necessarily the models themselves) is overly simplistic, which can at least be partly explained by the date of the actual work. The considerable research conducted in this area since $1980-1981$ is not referred to in the report.

Numerous assumptions are made regarding such issues as corrosion processes, including the relative importance of localized corrosion; radiation effects; pitting depth; and relevance of corrosion in low ionic strength seawater at ambient temperature. These assumptions are essential to the choice of materials and the determination of a corrosion allowance. The applicability of many of these assumptions is suspect.

Using American Society of Mechanical Engineers' standard tables for estimating structural allowances seems reasonable but not overly conservative. Relatively simple (perhaps overly simplistic) models are used to estimate temperature versus time profiles. The characterization of waste form properties is incomplete, especially with regard to consolidated spent fuel. Many of the constraints (e.g., temperature limits) are not discussed in sufficient detail to judge their applicability. Uncertainties in the limits are generally not diccussed. For example, $230^{\circ} \mathrm{C}$ is deemed acceptable for the maximum salt temperature (but not $240^{\circ} \mathrm{C}$ ?).

The basis for choosing the overpack material is highly questionable, whereas the basis for selecting canister materials is hardly discussed. In general, insufficient use is made of information available in the literature. Also, no method is given for extrapolating short-term corrosion data to the long term. Finally, the method for estimating pitting depth is inappropriate. Statistical analysis is required.

\section{Is the design output reasonable?}

In light of the above comments and the detailed commentary in other sections of this review report, the output is not reasonable for a "reference" design. 


\section{Are the design analyses properly done to address the specific issues?}

The issues of containment, retrievability, and isolation, as well as many other related issues, are addressed in general terms. However, a number of important issues are either never raised or, if raised, are dismissed with cursory arguments. One especially important example, in addition to those already mentioned in other sections, is waste form criticality. The reader is assured that criticality is highly improbable; however, no calculation has apparently been made. And, indeed, none are called for in the test program.

A second example concerns the assumption that the pitting corrosion depth is less thalı or equal to two times the general corrosion depth. Not only is this assumption not supported in the text, it is not even listed as one of the assumptions to be tested in the test program. The need to treat this quantity with appropriate statistical methods is overlooked.

Finally, the need to develop and test a procedure for extrapolating short-term corrosion data to the required 1000-year overpack lifetime is not mentioned; questions concerning model documentation, verification, and validation are neither clearly stated nor resolved; and the long-term properties of Zircaloy-clad fuel rods are not considered. ments?

\section{Are the design considerations adequately stated to cover all the require-}

Many design considerations are clearly connected to requirements. However, it is often difficult to trace the paths from design requirements not only to performance, but also to testing and verification. First, the correlation between the requirements stated in the report and NRC requirements is unclear. Indeed, NRC requirements are never mentioned. Second, the isolation requirement is so vaguely specified as to make compliance very difficult to judge. It is not obvious that NRC's isoiation or radionuclide release rate limitation is, in fact, satisfied and, if so, with what assurance. Third, the design requirements for the waste forms, particularly for consolidated spent fuel, are not discussed, except for vague statements about handling and interim storage. It is not even clear what the requirements are for incoming spent fuel rods (e.g., size, age, nuclide inventory, and physical condition). What assurance is there that the generic waste package's limitations would not be exceeded?

\section{Are the interpretations of the results correct?}

Reasonable assurance has not been given that all NRC requirements would be met by the proposed design. Only if cost effectiveness and related arguments for choosing low carbon cast steel are given much greater weight than fail-safe criteria can it be claimed that this steei is the material of choice. In fact, if any of several important assumptions (e.g., the importance of localized forms of corrosion or the a mount of brine available) is in error, then the choosing of low carbon steel will have been based on wrong interpretations of the analytical results. A particularly important example of misinterpretation of data occurs in App. B, where an Eh potential/pH diagram (Fig. B-1) is used to show that iron (at $25^{\circ} \mathrm{C}$ ) is in the passive region of its Eh-pH space for the specified range of $\mathrm{Eh}_{4}$ and $\mathrm{pH}$. Actually, iron is in the active corrosion region. 
Therefore, this diagram might have been used to show that iron should not have been selected as the overpack material.

7. Does the design meet the stated requirements?

In the judgment of this peer review panel, the reviewed report does not provide reasonable assurance that the requirements are or likely will be met. 


\section{PAGE-BY-PAGE COMMENTARY}

\begin{tabular}{|c|c|c|}
\hline Page & $\underline{\text { Lirie(s) }}$ & Comment \\
\hline iii & 2-6 & This sentence does not make sense. What does "to baseline" mean? \\
\hline iii & $13-14$ & $\begin{array}{l}\text { This definition for the "reference waste package" excludes the } \\
\text { crushed salt packing. On page } 1 \text { (lines 13-14), however, the term } \\
\text { "engineered salt repository waste package" is defined to include the } \\
\text { crushed salt packing. And, on page } 5 \text { (line 13), the "waste package" is } \\
\text { defined to include the crushed salt packing. These terms and their } \\
\text { definitions should be consistent. An appropriately labeled figure } \\
\text { might help. Any deviation from } 10 \text { CFR } 60.2 \text { should be clearly noted. }\end{array}$ \\
\hline $\mathrm{iii}$ & 29 & $\begin{array}{l}\text { The term "baselined" is not a common word. The term should either } \\
\text { be avoided or defined. }\end{array}$ \\
\hline 4 & 30-32 & $\begin{array}{l}\text { This sentence is confusing. The waste form is part of the engineered } \\
\text { waste package. }\end{array}$ \\
\hline 7 & & $\begin{array}{l}\text { Several units, abbreviations, and terms that are not in cummon usige } \\
\text { are encountered for the first time in this table. They should be } \\
\text { explained here in footnotes or in a glossary of terms. }\end{array}$ \\
\hline 7 & 42 & The relevance of the first footnote and datum is not clear. \\
\hline 9 & $10-11$ & $\begin{array}{l}\text { The word "additional" is confusing. Is "updated" meant? What is the } \\
\text { distinction between what has been done as a result of preparing this } \\
\text { report and "preliminary design activities"? }\end{array}$ \\
\hline 9 & $18-20$ & $\begin{array}{l}\text { The all-steel overpack design was apparently chosen in an earlier } \\
\text { Westinghouse study because it was cost effective. Is this the only } \\
\text { reason? The authors should provide ample background information on } \\
\text { why the all-steel design was considered best. Appendix G should be } \\
\text { referenced. Also, no information is given on the nature of the } \\
\text { canister material and the rationale behind its having been chosen. } \\
\text { Such information, with reference to an appropriate appendix or } \\
\text { section in the text, should be given. }\end{array}$ \\
\hline 12 & 27 & Are radiation limits not necessary for design? \\
\hline 21 & 4 & The three "interfaces" mentioned do not 8 \\
\hline
\end{tabular}


Page Line(s)

$21 \quad 18,25$

$21 \quad 17,25$

22

\section{Comment}

Should not drop test requirements like those in Table 3-5 be required for the canisterized waste forms? Also, why are the defense highlevel waste and commercial high-level waste canisters only filled to 85\% and 90\% of capacity? Is filling such a difficult problem? The 90\% figure contradicts the $85 \%$ figure used on page 4 (line 11).

The requirements for the waste canisters should be specified. They are important components of the waste package. What is the justification for the choice of material?

$7 \quad$ Does "gross waste form weight" include the weight of the canister?

11 What is the canister wall thiekness? Does "power output" include all escaping radiation?

19 What does "neutrons, reflected" mean? What conversion Eactor was used to convert from $\mathrm{Gy} / \mathrm{hr}$ to $\mathrm{mrem} / \mathrm{hr}$ for neutrons?

3 "Circular envelope" should be defined. Is the circular envelope different from the canister?

9-11 The sources of the ONWI information on geotechnical parameters and repository characteristics should be cited.

24 What are the anticipated conditions under which the waste forms and canisters will be stored, and do these conditions impose any design requirements?

The relationship between stress corrosion cracking and thermal expansion differential relative to the waste glass should be explained, and supporting references should be cited.

3 A note should be added saying that the maximum lithostatic pressure (15.4 $\mathrm{MPa}$ ) corresponds to about $686 \mathrm{~m}$. Also, the ambient temperature at depth matters.

What was the basis for selecting $250^{\circ} \mathrm{C}$ as the maximum salt temperature? Appropriate references should be cited. The amount of water released from the salt deposit certainly depends, to some extent, on the assemblage of hydrated minerals present. However, there is generally no threshold temperature above which hydrated water is released. Salt deposits rich in hydrated minerals would presumably be avoided anyway. Hence, a reasonable repository design criterion would be one that addresses the hydrated mineral content of the host rock. 
Page

Line(s)

28

9

$28 \quad 11$

29

1

29

$34 \quad 14-15$

36

37

37

39

48

25-26

48

26-29

49
Will the absence of an air gap yield a lower overpack surface temperature but a higher salt temperature? How will the absence of

an air gap affect the temperature history of the overpack?

What is meant by "shielded storage"?

What is the source of these data?

See the comment regarding page 34 (line 14). Buckling could also make retrieval of the weste form impossibie. erroneous. If the overpack were to buckle, the waste form could be damaged, which could alter its ultimate resistance to leaching.

A source shouid be cited for the assertion that "stresses in the weld, due to expected loading conditions, are low and essentially compressive." How likely are residual stresses and changes in microstructure in or near the heat-affected zone?

\begin{abstract}
"Small fiaws ... are not expected either to propagate due tu structural loading or provide sites for accelerated corrosion penetration under expected corrosion condicions." This questionable assertion needs substantiation because such flaws are usually good sites for initiation of stress corrosion cracking. What is the depth sensitivity of the MT inspection and, hence, the definition of a small flaw?
\end{abstract}

The assumption that the "weld will be large enough" needs verification. 


\begin{tabular}{|c|c|c|}
\hline Page & Line(s) & Comment \\
\hline 58 & $18-19$ & $\begin{array}{l}\text { Are the material temperature limits really that critical? What are } \\
\text { the uncertainty bounds on these limits? }\end{array}$ \\
\hline 58 & $29-31$ & $\begin{array}{l}\text { Reference is made to Sec. } 4.3 \text {, but that section does not contain the } \\
\text { indicated information. }\end{array}$ \\
\hline 59 & & $\begin{array}{l}\text { Details regarding } \mathrm{kW} / \text { package, W/area, age of waste at burial, etc., } \\
\text { should be added to the caption. }\end{array}$ \\
\hline 60 & 18 & $\begin{array}{l}\text { Are there any data to show that exposure to temperatures of } 480^{\circ} \mathrm{C} \text {. } \\
\text { for extended periods and to temperature transients to higher and } \\
\text { lower values during processing, shipping, interim storage, and } \\
\text { emplacement will not affect the resistance of the waste form and } \\
\text { canister to leaching attack? }\end{array}$ \\
\hline 61 & & $\begin{array}{l}\text { Details regarding } \mathrm{kW} / \text { package, W/area, age of waste at burial, etc., } \\
\text { should be added to the caption. }\end{array}$ \\
\hline 62 & & $\begin{array}{l}\text { Details regarding } \mathrm{kW} / \text { package, W/area, age of waste at burial, etc., } \\
\text { should be added to the caption. }\end{array}$ \\
\hline 62 & & $\begin{array}{l}\text { The temperatures of fuel rods in consolidated spent fuel are shown to } \\
\text { remain above } 300^{\circ} \mathrm{C} \text { for about } 20 \text { years after emplacement. How will } \\
\text { this affect the fuel rods and canister, if at all? The fuel rod } \\
\text { temperature limit is set at } 375^{\circ} \mathrm{C} \text {, but how reliable is that limit for } \\
\text { long-term performance? }\end{array}$ \\
\hline 64 & $9-10$ & $\begin{array}{l}\text { No reason is given for dismissing the possibility of a higher degree of } \\
\text { localization of attack in the weld zone. }\end{array}$ \\
\hline 65 & 8 & $\begin{array}{l}\text { "Local corrosion effects, except for pitting, are not expected." This } \\
\text { very important assertion should be substantiated. }\end{array}$ \\
\hline 65 & $8-11$ & $\begin{array}{l}\text { "Studies in saline waters" do not support the conclusion that the } \\
\text { pitting factor will not exceed two for the reference design. }\end{array}$ \\
\hline 65 & $26-32$ & Are notch effects at the pit considered in the structural calculations? \\
\hline 65 & 31 & The term "structural capability" should be defined. \\
\hline 86 & $18-19$ & be given for this statement. \\
\hline
\end{tabular}




\begin{abstract}
Page Line(s)
$66 \quad 30-32$

68

$6 ?$

$71 \quad 12$

$71 \quad 17-29$

$71 \quad 24-29$
\end{abstract}

$72 \quad 16$

72 The assumption that the fluids are "stagnant" is unsupported.

72 31-34 The brine may be neither stagnant nor anoxic. The arguments on page 72 give little assurance that the reference waste forms (especially that for the consolidated spent fuel) will be able to meet the isolation requirements, except possibly under the conditions specified by the authors (not necessarily the conditions in the repository).

73 10-13 Is this possibility being investigated further? In addition, could radiolysis and the effects of radiation on the waste form itself enhance leachability? Where is this issue addressed? Will it be examined in the test program?

$73 \quad 17$ The use of the term "ore-like state" is questionable. It contradicts the earlier description of the corrosion residues as being in a gel-like state (p. 73, line 9). 
Page Line(s)

Comment

$73 \quad 20-21 \quad$ What are "suitably dispersed and mobile molecular fragments"?

$77 \quad 19 \quad$ What does it mean to say that "CSF [consolidated spent fuel] should not constitute a criticality hazard" if the calculation had admittedly not yet been performed? Are there no inaications of plans for these calculations in the test program? It should be noted that criticality is defined as $k_{\text {eff }}=1.0$, where $k_{\text {eff }}$ is the effective reproduction constant. The requirements (Sec. 3.1.5) specify that $k_{\text {eff }} \leq 0.95$.

$78 \quad 18 \quad$ "Substantial plastic flow" of what?

85 12-13 Are the codes ANISN and WECAN proprietary, or are they in the public domain? No references are given to ANISN code documentation, verification; or validation. Comments regarding WECAN are given in connection with App. D.

Detailed characterization data on fuel rod batches as a function of reactor identity are given in Science Applications, Inc. (1980). Although the number of reactors is very limited, the data are very detailed. While the assumption that earlier reactor designs used smaller arrays is generally valid, it is probably not valid to assume that rod dimensions are constant over time for a given array size. Also, the problem of stainless-steel-clad fuel rods from the Connecticut Yankee, San Onofre, and LaCrosse reactors must be audressed.

$89 \quad 2-3 \quad$ Since the extent of variation in fuel types is not known, how can a standardized waste package be defined at this time? Can meaningful design requirements based on incoming waste forms be given? If they can, what are they? How does one know that the nuclide inventory, and therefore the anticipated temperature as a function of time for each incoming waste form, will meet design requirements? This type of information should be discussed.

$92 \quad 21$ Has allowance been made for changes in rod diameter caused by creep resulting from mechanical interaction between the pellets and the cladding?

92 29-30 Given that localized deformation due to mechanical interaction between the pellets and cladding occurs in reactors, it is unreasonable to expect rods to touch line to line. 
Page Line(s)

$99 \quad 24-27$

The lack of integrations is a serious shortcoming. It is difficult to correlate the myriad assumptions and assertions made at various places in the report with specific verification test plans. The responsiveness of the testing programs to regulatory requirements is by no means clear. Also, the connections are not always clear between short - and long-term efforts.

99 27-33 This part of the paragraph needs more thought. Establishing the amount of brine expected on a site-specific basis should certainly have high priority, as should demonstrating the feasibility of performing and exerting quality control over the remote closure welding of the overpack. However, serious concerns are expressed in this review report regarding early mind sets with respect to such items as material choices (e.g., low carbon steel overpack and stainless steel canister) and the effects of local corrosion and radiation. Hence, care must be taken to avoid developing a research and testing program that is too narrow in scope at the onset.

$100 \quad 18$ Gamma radiolysis will generate other gaseous species. In other words, the vapor state will not be pure gaseous water.

$100 \quad 18-20$ "Current estimates of the volumes of brine and/or vapor deliverable to each package range over several orders of magnitude." This statement is inconsistent with Sec. B.3.3.2, Table B-1, which indicates that estimates of water delivery were all in the $\sim 100-\mathrm{L}$ range. Where do the several orders of magnitude come from? References should be cited.

$100 \quad 27$ What is a "solutiun/dissolution mechanism"?

1012 The authors should differentiate between Darcy and Knudsen flow. Only Darcy flow was considered in App. C.

$101 \quad 6-7$ The temperature gradient $\nabla \mathrm{T}$ is defined as positive in the direction of increasing temperature. The phrase "temperature gradient leading away from the hot waste package" is a contradiction in tarms.

101 During the time that the repository is open, all surfaces, including the excavated material, will be exposed to ambient air. Salt, being hygroscopic, will take up moisture from the air. Has this source of water been evaluated? 
Page Line(s)

$101 \quad 19$

$101 \quad 27-28$

$101 \quad 29-32$

102

102

$103 \quad 10-17$

$104 \quad 3-18$

$105 \quad 3-5$

$106 \quad 8$

\section{Comment}

The basis for selecting a water content of $0.75 \mathrm{wt} .-\%$ should be specified. Although this percentage is probably conservative for domal sait, it may not be for bedded salt.

What is the reasoning behind the assumption that water delivery by brine or vapor, if treated as occurring independently, is conservative? Brine migration can transport water from the interior of a crystal to grain boundaries, where the vapor transport mechanism may take over. It is not obvious that treating these mechanisms separately is conservative.

It is erroneous to assume that only brine or pure water vapor can come into contact with the overpack. Radiation may generate other gaseous species that could be carried with the water vapor. For example, the presence of gaseous $\mathrm{HCl}$ could enhance the corrosion rate.

19 Improved models and computer programs head the list of work items, yet no justification is given for this activity. It is not clear whether the existing models are inadequate, or merely their application to this problem. Doing the best job possible with the existing models should be the main emphasis. If the models prove inadequate, they should be refined. Also, references covering the documentation, verification, and validation of the existing models should be added.

28 References should be cited to support the statement that there is a wide range in the values of these properties.

Planning the long- and short-term tests concurrently is a good idea. However, alternative material choices should be included in the tests as a backup, in the event that choosing low carbon steel proves to be a mistake. Some of the tests should be designed to last for the duration of the retrievability period.

The list does not include the assumption that local corrosion, other than pitting corrosion, is not important. Also omitted is the assumption that pitting depth is less than or equal to two times the general corrosion depth. These assumptions should be tested. It may be that there are plans to do so because both general and local corrosion are mentioned in lines $25-28$.

Pressure should be included as one of the test variables.

The effects of physical contact (perhaps nenuniform) between rock salt and the overpack surface is not mentioned. How will such effects be simulated? 
Page Line(s)

Comment

106 8-10 Chemical stresses due to $\mathrm{NO}_{2}, \mathrm{MgCl}_{2}$, sulfide, and carbonate concentrations should also be considered.

$106 \quad 25-29 \quad$ Further explanation is needed.

106 What is meant by "to become a blocking variable"?

107 What is meant by "cost effective"? Compared with what?

10920 "Expected brine conditions" are not delineated -- neither the composition of the brine nor the expected quantities.

110 The status of leaching performance is unclear. The references cited are not up to date.

110 More recent work (e.g., Panno and Soo, 1983) indicates that brines can become very acidic or very basic at different times after emplacement, with catastrophic effents on the leach rates of the waste forms. "Radiolysis of aerated water containing nitrogen" would indeed produce $\mathrm{NO}_{3}{ }^{-}$, but this species is a beneficial scavenger that would reduce radiolytically produced $\mathrm{OH}^{-}$by up to three orders of magnitude (Burns et al., 1982). Thus, in a real repository, radiolysis of the leachate may not have that dramatic an effect on the silicate leach rate. The very slow flow rate of water will probably be the rate-determining factor controlling glass dissolution in the repository environment.

$110 \quad 33$ What is meant by "overpack design without a backfill"?

111 Are all tests to be conducted in the laboratory, or are field tests planned as well?

111 How will this be done?

111 27-29 Does this sentence mean that the pressure was $60 \%$ in excess of lithostatic pressure? If so, what were the experimental conditions that led to this situation? Are these conditions likely to arise naturally?

Given that so many things are still undefined, the justification for the array of tests represented by this test matrix and the objectives should be clarified. Also, what does "surface/volume" mean? Why use stagnant flow conditions? It is not obvjous that oxic conditions can substitute for radiation. What types of experimental setups are envisioned? And, finally, the need for investigating the long-term performance of Zircaloy-clad fuel rods is not mentioned. Is this alloy well understood? 
Page Line(s)

116 9-10 The term "triangular pitch" should be explained?

11618 While the approach is conservative, consideration should be given to degradation in conductance between rods caused by release of fission gas as a result of rod failure during the 1000-year containment period.

118 An update of the Avery Island brine migration tests (Krause, 1983) stresses that the brine migration studies looked only at fluid inclusions. However, fluid inclusion studies do not correspond well with the real situation, in which most of the water is found in hydrated minerals.

11914,23 "There is a good chance that radiation effects [on brine migration] need not be simulated as is planned for some of the Asse emplacements." This downplaying of possible radiation effects is premature and has not been justified with appropriate citations. Radiation effects are likely to depend on rock composition, temperature, and strain state.

119 29-31 The short-term program did not include testing of alternative materials. The impression is given on page 103 (line 6) that only the "waste package material," presumably type 1018 steel, will be tested. If this impression is erroneous, then the intention to test several alternative materials should be clearly stated. If several alternative materials are not to be tested in the short-term program, then that intention should perhaps be reconsidered.

$120 \quad$ "Field testing" of what?

120 13

Section 7.1.4 refers to laboratory testing of leaching rates.

120 17

Where is this work discussed?

124 26-28 The cited criteria may be conservative for the intended routine applications, but it is not certain that they are conservative for the waste repository application.

$125 \quad 1-2$

It is erroneous to say that "failure definition can be limited to penetration or rupture of the package." (Is overpack meant here?) If the overpack buckles, it may cause the waste form to break up. It may also make retrieval of the waste form virtually impossible without overcoring and removal of the entire waste package. 
Page Line(s)

Comment

125 26-27 This unsupported statement is overly optimistic and misleading. If any of several important assumptions in the report prove to be erroneous, then the current design may be inadequate.

129 9-10 Substitute the term "overpacks" for "waste packages," since the waste form is part of the waste package.

129 16-18 This statement remains to be demonstrated.

$12926 \quad$ No limit has been set for consolidated spent fuel.

$133 \quad 5-6 \quad$ This item is an unacceptable overstatement.

$133 \quad 7-10 \quad$ The first part of this statement is acceptable. However, using the term "reference package designs" is confusing. If a "reference" design is one that is a viable option and that is to serve as a benchmark, or reference, against which to compare other viable options, then the use of the term in this context is erroneous.

133 11-12 No real cost analysis, other than a consideration of the cost of metals, is reported. Many other factors must be critically evaluated before such a judgment can be made. If other factors have already been delineated and critically evaluated, that analysis should have been presented.

Eh $=$ (?) 0.0 volts, $5<(?) \mathrm{pH}<(?) 8$.

141 26-27 It was not mentioned previously that "there may be a throughput of several hundred kilograms as vapor prior to any possibility of condensation." Where would this vapor come from, and what would be its composition? Would not the vapor also attack the overpack? On page 153, it strites that the corrosion rate resulting from expostre to steam (pure viater) is orders of magnitude less than that resulting from exposure to an aqueous brine solution. However, Westerman et al. (1982) report a case where vapor-phase corrosion may have exceeded liquid-phase corrosion.

143 24-27 To state that "the primary geochemical attributes ... are Eh ... and $\mathrm{pH}^{\prime \prime}$ totally ignores the importance of rock salt composition.

145 13-31 The analysis seems to contradict information summarized in Fig. B-1. The projected $\mathrm{pH}$ and $\mathrm{Eh}$ values $--5-8$ and -0.21 to -0.23 , respectively -- place iron in the corrosion region of its Ehpotential/pH space, not in the passive region. On the basis of the diagram, iron should not be the metal of choice for waste packages to be emplaced in salt. In addition, the work eited in lines 15, 21 , and 22 does not include radiolysis effects. 
Page Line(s)

$145 \quad 28$

$147 \quad 1-9$

$147 \quad 26$

148

149

150

28,29

150

Comment

The reference "Krauskopf, 1979" is not included in the reference list.

Equations do not necessarily describe "stoichiometric corrosion requirements" but rather one chemical pathway. The partial transformation of iron to $\mathrm{Fe}^{++}$stilı constitutes corrosion; in this case, the anoxic:oxic water requirement is $2: 1$, not $4: 1$. The effect of radiolysis is ignored.

The assumptions leading to the values $3700 \mathrm{~kg}$ and $950 \mathrm{~kg}$ of brine should be explained. How were these quantities of dissolved solids figured?

11 The reference "Powers, 1978" is not included in the reference list.

The calculation showing that $7 \%$ of the water content of the repository is required to corrode the entire overpack assumes that no unexpected supply of water will present itself during the 1000-year containment period. In addition, since salt is hygroscopic, both the backfill and the repository walls will absorb water from the atmosphere before closure. The backfill may even have been exposed to precipitation during storage. These expected phenomena and estimates of their associated water uptake should have been addressed. Also, the water content of the salt should be site specific; $0.75 \%$ is conservative in some cases but not in all.

25 "Terminal times" are not listed in Table B-1. Are these values actually "transport times"?

It was probably true in 1980 that the estimates of water quantities were "based on the most sophisticated and carefully reasoned mechanisms available," but it is questionable whether they still are. The model implementation is overly simplistic. Only Darcy flow is included for the vapor transport calculations, whereas Knudsen flow is generaily regarded as more adequate. Also, stress-gradient transport is not even mentioned. Even more significantly, the latest reference is dated 1981 (see related comments regarding page 189).

In accord with the comments for lines 26-27 immediately above, the point that the water quantity estimates "are unproven and that there is considerable uncertainty in several supporting parameters" is certainly valid.

30-31 The quotation from Jenks and Claiborne (1981) is strongly supported by the peer review panelists. 
Page Line(s)

$153 \quad 15-19$

$155 \quad 12-14$

157

158

159

160

160

163

163

Comment

The steam atmosphere will contain radiolytic species and will not be farticularly benign. Furthermore, will the brine remain anoxic in the presence of air in the buckfill material? Also, see comments regarding page 141 (lines $26-27$ ).

The need for experiments is clear. Further analysis is also required. The argument of the preceding paragraphs is quite interesting but not convincing. It needs to be alred in the literature. Alternative hypotheses may also be posed. For examp!e, it is assumed in paragraph 2 that condensed water will remain "walled of $f$ " (i.e., prevented from returning to the waste package) by a ring of dense salt accretion. It could as easily have been postulated that deformation forces may nucleate paths to the overpack, thereby allowing water contact.

18-19 Selecting $30 \mathrm{~L}$ as the amount of water to be delivered to the overpack depends on the permeability decreasing to a negligible value after a period of 10 years. This decrease is attributed to the developing lithostatic pressure, which will reach a maximum of $15.4 \mathrm{MPa}$ after 10 years. However, no information, data, or theory is presented to support this claim.

2-4 The basis for this conclusion seems highly conjecturai. The entire argument is interesting but should be aired in the literature. The conditions under which such a result could reasonably be expected are far from clear. If the argument turns out to be erroneous, then substantially more water may arrive after initial condensation, especially if the predominant mechanism turns out to be brine inclusion migration, perhaps coupled with other transport mechanisms.

The term "water condensate" is clearer than "condensed water," since it is not likely to be pure water.

23-32 This discussion ignores the possible input from radiolysis.

26 "E" should be replaced with "C."

23 Hydrogen gas can also be produced by radiolysis of the liquid brine, vapor phases, and hydrated salts.

24-25 The possible consequences of hydrogen embrittlement seem too important for them to be dismissed so lightly. A large volume of water may not be necessary to cause severe damage. 
Page Line(s)

$164 \quad 23$

165

165

165

$165 \quad 20-31$

165

166

174

174

176

177

\section{Comment}

Experimental results (Patil et al., 1984) indicate that, under aqueous conditions, significant chemical reducing effects may occur as a result of irradiation.

\section{4-5 Substantiating references should be cited.}

5 Evidence shows that radiation (principally neutrons) can alter the character of oxide films. In Zircaloy alloys, a neutron flux causes the oxidation rate to increase.

\section{0-14 Substantiating references should be cited.}

20-31 Crushed salt may not be an appropriate medium with which to pack the boreholes because of the formation of colloidal sodium. Addition of $\mathrm{CaO}$ would aggravate the corrosion problem. Brines associated with irradiated salt react to form $\mathrm{NaOH}$ (Panno and Soo, 1983). This "benign basic $\mathrm{pH}^{\mathrm{H}}$ can reach levels ( $\left.\mathrm{pH} 14\right)$ that seriously compromise the integrity of the waste form.

\section{2-23 Substantiating references should be cited.}

3-6 Extensive research has been done on the effects of radiclysis on rock zalt (e.g., Jain and Lidiard, 1977; Levy, 1983). Even if "liquid water ingress is limited," the waste container will be surrounded by brittle, unstable, degraded salt and up to $300 \mathrm{~kg}$ of reactive colloidal sodium.

4-5 "The narrowness of this projected band suggests a good fit." A good fit to what? The confidence interval applies only to the data, not to any projected range outside the original data range.

"Sec. B.4.1" should be changed to "Sec. B.4.2."

15-23 The judgment that corrosion rates in seawater are greater than those in brine needs substantially more justification. What about the effects of brine composition, elevated temperature, and radiation, not to mention the effects of siress and the influence of welding?

33 The statement that "unalloyed carbon steel should not be susceptible to stress corrosion failure" should be supported by literature citations. It may be true for annealed materials, but not in general. 
Page Line(s)

$180 \quad 24-27$

$183 \quad 24-26$

189

10

$189 \quad 28-30$

$189 \quad 30-31$

190

190

190

29

$191 \quad 1-4$

Comment

This statement directly contradicts numerous earlier statements that local corrosion other than pitting is not considered important. No data have been presented to support the notion that the proposed low carbon steel material will be immune from microstructural changes that would lead to enhanced susceptibility to local corrosion processes other than pitting.

The effects of radiation are not mentioned. Would they alter this general conclusion?

The three major proposed mechanisms should at least be discussed. A third mechanism -- liquid transport driven by a stress gradient in the salt -- should be added to the migration of brine inclusions in a temperature gradient and vapor-phase transport along connected porosity.

The assumptions "that inclusion motion is not affected by grain boundaries, and [that] relationships developed for motion in individual crystals will be applied to bulk salt," are oversimplistic.

Sections C.1 and C. 2 may have been "the best available description of liquid inclusion motion" and vapor migration as of 1980 , which is the year of the most recent reference cited in the report. However, much research on these topics has been done since then. For example, grain boundary effects have been considered, equations have been refined, and physical parameters have been better evaluated.

5-6 Much of the "large degree of variability" can be understood in the context that the migration velocity depends on several factors (not just the local temperature gradient), including brine composition; concentration gradient; diffusivity of salt within the liquid; undersaturation and supersaturation required at the dissolution and precipitation interfaces, respectively; inclusion size; and dislocation density.

14 The definition should read: $V / G=$ migration velocity per unit temperature gradient $\left(\mathrm{cm}^{2} \mathrm{yr}^{-1}{ }^{\circ} \mathrm{C}^{-1}\right)$.

On page 101 (line 19), it states that a water content of $0.75 \mathrm{wt} .-\%$ was assumed in the modeling calculations, not the "0.001 weight fraction" stated here.

Has the MIGRAIN code been validated? Is this code in the public domain? What was the extent of Westinghouse's independent verification of this code's applicability to solving the equations? Are the equations themselves complete and correct? 
Page Line(s)

191

8-12

$191 \quad 19-21$

$191 \quad 24-25$

$192 \quad 1-23$

$196 \quad 1-3$

200

201

204

12-14

19-26

204

16,21

205

\section{Cominent}

This important point is obscured by an almost unintelligible sentence.

This sentence implies that the model treats water vapor as coming from evaporation of water from brine or from hydrated minerals present in the rcck salt. However, this second source of water is not discussed further in App. C. Does the model ti'eat hydrated minerais?

For salt, the noininal pore radius of the connected porosity is so small that the Darcy component of the flux is negligible. To state that "only Darcy flow is eurrently being modeled" used to be true but only during the early development of the vapor-transport model. The Knudsen diffusion component of the flux is now also generally included (Shefelbine, 1982).

Boiling-point elevation (i.e., vapor-pressure depression) of saturated salt solutions is well understood, but this fact does not make it "clear that the remaining brine solution in the salt must be in local vapor pressure equilibriLm with the water vapor flowing past the brine."

The two assumptions stated here are overly simplistic and neglect other parameters.

This paragraph states several assumptions that are commonly made in thermal analyses, but without any discussion of their relative importance.

The location and orientation of the three views should be shown on the column, along with the horizontal scale.

The significance of this comment is not clear. The thermal properties, waste decay rate, and ambient temperature were all different in Claiborne et al. (1980). Consequently, any agreement in peak temperatures appears to be fortuitous and thus of no particular significance. The comparison with basalt seems irrelevant.

Why were the boundary values $15^{\circ} \mathrm{C}$ and $34^{\circ} \mathrm{C}$ chosen?

Although Table D-1 gives the material properties used in the repository model, no source is given for these properties. The numbers are not the same as those given in Claiborne et al. (1980). This discrepancy is bound to be confusing when the abstract states that the report provides conceptual designs to "baseline." 
Page Line(s)

205

206

209

$209 \quad 27-28$

$214 \quad 1-3$

218

219

242

1

243

\section{7}

The entire report as well as the tables on this page should use SI units. Further, the tables should state that the equations giving the temperature dependence of the thermal conductivity of salt and air use temperatures given in degrees Celsius.

Table D-3 includes two columns labeled "CHLW." The only apparent difference is that the center column is for "five years out of reactor." Since no calculations are mentioned for waste of this age, why is this column included? Also, nc decay characteristics are given for "DHLW," for which thermal results are given. Perhaps one of these columns should be labeled "DHLW." Further, no source is given for the data. Why are discrepancies found when these data are compared with those in Claiborne et al. (1980), who used Kisner et al. (1978) as a source?

Jargon such as "triangular pitch rod arrangement" should be avoided.

Although a radiation-only heat transfer mechanism may be conservative in light of what is known about the process, such conservatism is not needed. This calculation will be complicated if ratchetting of the clad caused by interaction between the pellets and the cladding is considered.

Temperature drops through the oxide layer can be significant, at least in $\mathrm{ZrO}_{2}$. It is not clear whether such drops should be neglected. Also, have thermal analyses been made for a canister that is not concentric with the overpack?

5 What temperature was assumed for the structure calculations for the heads?

14-15 Strain hardening in low carbon steel will be very small. The strain hardening exponent is probably between 0.1 and 0.15 .

This statement disagrees with data given in Cleary and Green (1967), where it states that the corrosion rate in steels is very dependent on the distribution of carbon, the dissolution rate increasing markedly with decreasing pearlite spacing in deaerated acids. Also, phosphorus and manganese were found to be detrimental to the corrosion rate. Although these comments do not apply to corrosion in the presence of anoxic brine solutions, the independence of the corrosion rate with regard to chemistry should be demonstrated.

The effective earbon content given here (above $0.40 \%$ ) contradicts the value of $0.30 \%$ on page 241 . 
Page Line(s)

Comment

$244 \quad 20$

The third asterisk is missing after $205 * *$.

24424 The equal sign is missing after 0.40 . 


\section{REFERENCES}

Burns, W.G., et al., 1982, Radiation Effects and the Leach Rates of Vitrified Radioactive Waste, Nature, 295:130-132.

Choi, H., et al., 1982, Stress Corrosion Cracking of ASTM A508 CL 2 Steel in Oxygenated Water at Elevated Temperatures, Corrosion, 38:136.

Clesiborne, H.C., L.D. Rickertson, and R.F. Graham, 1980, Expected Environments in High-Level Nuclear Waste and Spent Fuel Repositories in Salt, Oak Ridge National Laboratory Report ORNL/TME-7201.

Cleary, H.J., and N.D. Greene, 1967, Corrosion Properties of Iron and Steel, Corrosion Science, $7: 821-831$.

Davis, M.S., and D.G. Schweitzer, 1983, Draft Technical Position Subtask 1.1: Waste Package Performance after Repository Ciosure, U.S. Nuclear Regulatory Commission Report NUREG/CR-3219, Vol. 1.

Jain, V., and A.B. Lidiard, 1977, The Growth of Colloidal Centers in Irradiated Alkali Halides, Philosophical Magazine, 35:245.

Jenks, G.H., 1979, Effects of Temperature, Temperature Gradients, Stress, and Irradiation on Migration of Brine Inclusions in a Salt Repositom, Oak Ridge National Laboratory Report ORNL-5526.

Jenks, G.H., and H.C. Claiborne, 1981, Brine Migration in Sait and Its Implications in the Geologic Disposal of Nuclear Waste, Oak Ridge National Laboratory Report ORNL-5818.

Kisner, R.A., et al., April 26, 1978, Nuclear Waste Projections and Source-Term Data for FY 1977, Oak Ridge National Laboratory $\mathrm{P}$ sport Y/OWI/TM-34.

Krause, W.B., 1983, Avery Island Brine Migration Tests: Installation, Operation, Data Collection, Analysis, Office of Nuclear Waste Isolation, Battelle Memorial Institute, Columbus, Ohio, ONWI-190(4).

Levy, P.W., 1983, Radiation Damage Studies on Natural Rock Salt from Various Geological Localities of Interest to the Radioactive Waste Disposal Program, Nuclear Technology, 60:231-243.

Macdonald, D.D., and B.C. Syrett, 1979, Potential-pH Diagrams :Or Iron and Nickel in High Salinity Geothermal Brine Containing Low Concentrations of Hydrogen Sulfide, Corrosion, 35(16):471-475.

Panno, S.V., and P. Soo, 1983, An Evaluation of Chemical Conditions Caused by Gamma Irradiation of Natural Rock Salt, J.S. Nuciear Regulatory Commission Report NUREG33658. 
Park, J.R., 1983, Impedance Studies of the Corrosion of Carbon Steel in ChlorideContaining Aqueous Solutions at Elevated Temperatures, Ph.D. thesis, Ohio State University, Columbus.

Patil, S.F., et al., 1984, Chemical Effects Induced by Gamma-Irradiated Salts in Aqueous Medium, Int. riational J. Applied Radiation and Isotopes, 35:459-462.

Science Applications, Inc., 1980, EPRI Fuel Performance Data Base: General Description, prepared for Electric Power Research Institute, EPRI NP-1489.

Shefelbine, H.C., 1992, Brine Migration: A Summary Report, Sandia National Laboratories Report SAND-82-0152.

Stein, R., 1985, Acting Head, Engineering and Licensing Division, Office of Civilian and Radioactive Waste Management, U.S. Departinent of Energy, Memorandum to J. Neff et al., Salt Repository Project Office, Common Terminology of Waste Package Components.

Steinbaugh, R.E., 1979, Retrieval of Canistered Waste at the Waste Isolation Pilot Plant, Sandia National Laboratories Report SAND-79-1239.

U.S. Department of Transportation, Jan. 1, 1984, Shippers - General Requirements for Shipment.s and Packagings, Code of Federal Regulations, 49 CFR Part 173.

U.S. Environmental Protection Agency, Dec. 29, 1982, Environmental Standards for the Management and Disposal of Spent Nuclear Fuel, High-Level and Transuranic Radioactive Wastes, 40 CFR Part 191, Fed. Reg., 47(250):58196-58206.

U.S. Mining Safety and Health Administration, Jan 1, 1984, Safety and Health Standards - Metal and Nonmetal Underground Mines, Code of Federal Regulations, 30 CFR Part 57.

U.S. Nuclear Regulatory Commission, Jan. 1, 1984a, Disposal of High-Level Radioactive wastes in Ceologic Repositories, Code of Federal Regulations, 10 CFR Part 60.

U.S. Nuciear Regulatory Commission, Jan. 1, 1984b, Standards for Protection against Radiation, Code of Federal Regulations, 10 CFR Part 20.

U.S. Nuclear Regulatory Commission, Jan. 1, 1984c, Domestic Licen-ing of Production and Utilization Facilities, Code of Federal Regulations, 10 CFR Part 50.

U.S. Nuclear Regulatory Commission, Jan. 1, 1984d, Packaging and Transportation of Radioactive Material, Code of Federal Regulations, 10 CFR Fart 71.

U.S. Nuclear Regulatory Commission, Oct. 1984e, Draft Generic Technical Position: Waste Package Reliability. 
U.S. Nuclear Regulatory Commission, Jan. 17, 1985, Disposal of High-Level Radioactive Waste in Geologic Repositories: Amendments to Licensing Procedure, Fed. Reg., $50(12): 2579-2590$.

Westerman, R.E., S.G. Pitman, and J.L. Nelson, Sept. 1982, General Corrosion, Irradiation-Corrosion, and Environmental-Mechanical Evaluation of Nuclear-WastePackage Structural-Barrier Materials, Pacific Northwest Laboratory Report PNL-4364.

Westinghouse Electric Corporation, Nov. 1984, Waste Package Reference Conceptual Designs for a Repository in Salt, WTSD-TME-001, Rev. A. 
$55 / 56$

APPENDIX A

U.S. DEPARTMENT OF ENERGY LETTER

KEQUESTING PEER REVIEW 


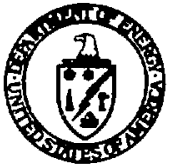

Department of Energy

Chicago Operations Office

Salt Repository Project Office

505 King Avenue

Columbus, Ohio 43201-2693

Commercial (614) 424-5916

F.T.S. 976-5916

January 24, 1985

Wyman Harrison

EES-362

Argonne National Laboratory

9700 South Cass Avenue

Argonne, IL 60439

Dear Dr. Harrison:

SUBJECT: REVIEW OF REPORT ENTITLED, "WASTE PACKAGE REFERENCE CONCEPTUAL DESIGNS FOR A REPOSITORY IN SALT"

We would appreciate your forming a panel to review the attached draft report, "Waste Package Reference Conceptual Designs for A Repository in Salt." This "eport was reviewed by an ONWI internal peer review group in May, 1984. The $\because \cdots$ report is also attached for your information. The present version has incorporated many of the comments resulting from the peer review grou'.

Again, this revised repori will be reviewed by ONWI and SRPO technical staff, $\mathrm{DOE}-\mathrm{HQ}$, and Fluor Engineers, Inc. AN!'s review should include, but need not be 1 imited to, the following points:

(a) Are the necessary assumptions described reasonable, and have they been verified for applicability?

(b) Are design methods appropriate?

(c) Is the design output reasonable?

(d) Are the design analyses properly done to address the specific issues?

(e) Are the design considerations adequately stated to cover all the requirements?

(f) Are the interpretation of the results correct?

(g) Does the design meet the stated requirements? 
W. Harrison

Page 2

Please complete the review and submit the final report to SRPO by March 4 , 1985. If you have any questions concerning this matter, please contact Roger Wu at FTS 975-5916.

Sincerely,

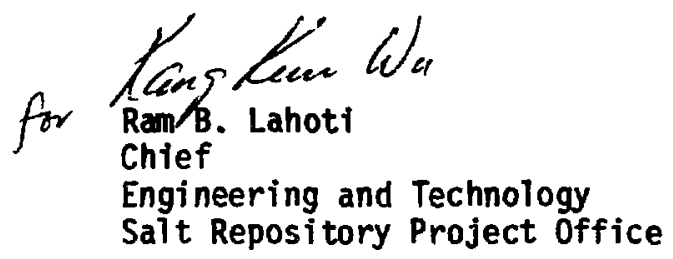

SRP0:KKW:max:5655B

Enclosures:

As Stated

CC: R. Wunderlich, SRPO, w/o encl.

J. Sherwin, SRPO, w/o encl.

S. Basham, ONWI, w/o encl.

ST\# 186-85 
$59 / 60$

APPENDIX B

CONCURRENCE SHEET 
$61 / 62$

APPENDIX B

CONCURRENCE SHEET

I concur that the Argonne National Laboratory report on Westinghouse Electric Corporation's report entitled Waste Package Reference Conceptual Designs for a Repository in Salt, Revision A, fairly represents my comments, where incorporated, to the peer review panel.
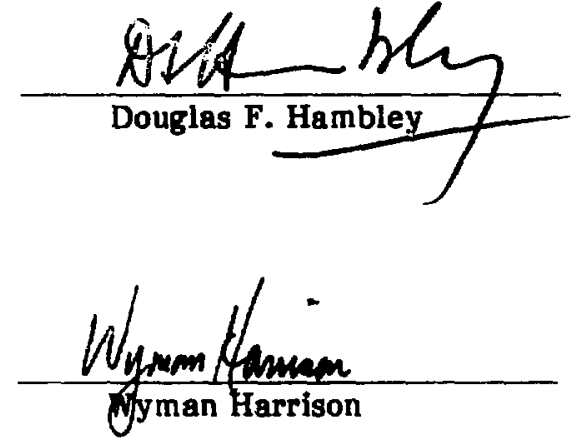

$\underset{\text { Amy B. Hull }}{\text { Cimgell }}$

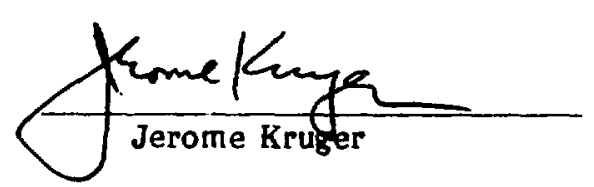

Atherdonalal
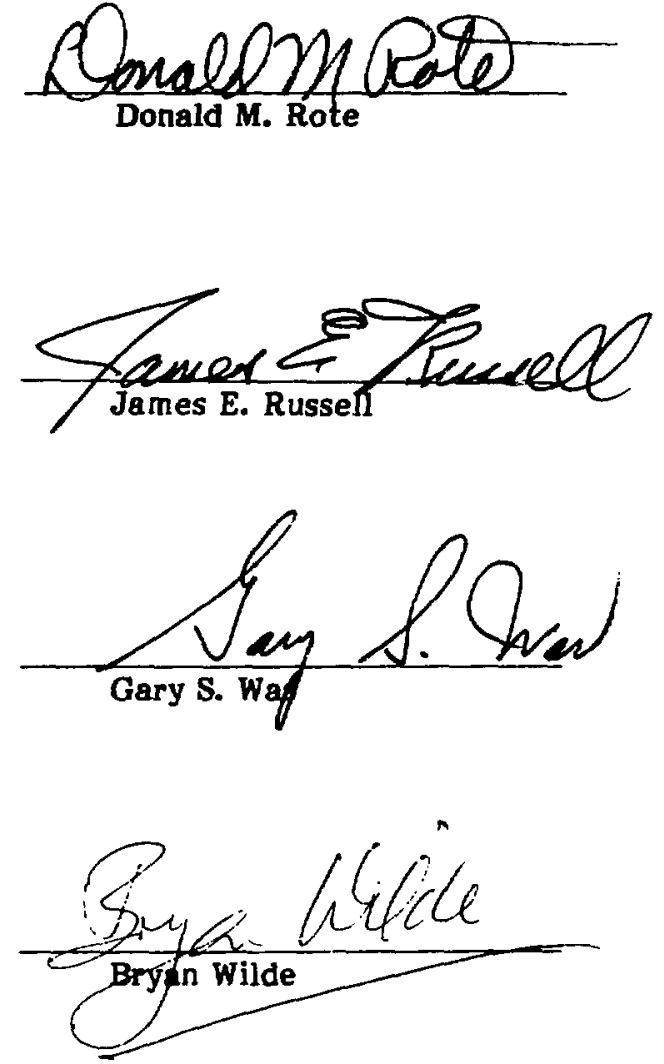


\section{APPENDIX C}

\section{RESOLUTION OF ONWI RESPONSES TO THE PEER REVIEW PANEL'S RECOMMENDATIONS AND PAGE-BY-PAGE COMMENTS}

A day-long meeting was held at SRPO on July 19, 1985, to begin the task of resolving differences between Argonne's recommendations and comments in the Summary of Recommendations and Sec. 6 of this report, respectively, and ONWI's responses thereto. The following individuals took part in the initial meeting: S.J. Basham, J.A. Carr, J.R. Cavanaugh, and J. Schornhorst from ONWI; R.B. Lahoti and K.K. Wu from SRPO; and W. Harrison and D.M. Rote from Argonne. The ONWI responses were made on their "Technical Comment Review and Response Form," copies of which are in the ONWI and Argonne quality assurance files for this peer rcview. Resolution of comments and responses continued intermittently through August 21,1985 , primarily between ONWI's J.R. Cavanaugh and Argonne's W. Harrison and D.M. Rote.

\section{RESOLUTION OF ARGONNE RECOMMENDATIONS}

Recommendation

\section{$\underline{\text { Resolution }}$}

The performance requirements for the reference conceptual design were those in the DOE/NWTS-33 series of documents. The Foreword that will be written for the design report will state that these documents provided the regulatory requirements for this work.

Same resolution as for recommendation 1 .

Some of the codes used were proprietary and some were not. Section 5.14 of the design report states that complete verification should be part of the next design step and that validation must be accomplished before licensing. Any codes used in the license application will be available to the public.

The major issues identified by Davis and Schweitzer (1983) were not available at the time the dcsign report was prepared. Uncertainties in the data and calculations not specifically addressed during the reference conceptual design phase will be examined in later design phases. The Foreword will identify which uncertainties were not addressed in the design report. 
Recommendation

\section{Resolution}

The required development programs will be established by ONWI, independent of the development program recommended in the design report. The ONWI program will support a licensing application. The Foreword will state that the recommendations regarding the development program, given in Sec. 7 of the design report, will be used as a basis for ONWI's program.

Appendix $G$ of the design report discusses the rationale for using carbon steel containers. Section 3.5.4 of that report states that cost and availability of material have to be secondary to functional performance requirements. The last sentence in the first paragraph of Sec. G.2 will be deleted.

A final choice of materials was not required by the design specifications for the reference conceptual design phase. Carbon steel was specified by ONWI as the material for the CSF canister and the containers. Final materials will be selected in later design phases.

Design of the waste forms for DHLW, CHLW, and CSF, as well as the canisters for DHLW and CHLW, was not included in the scope of work for the contract. These components will be designed ty other participants in the program. The Foreword will state that design of waste forms is not addressed in the design report.

Back-up alternative materials are included in the overall program plan, but were not specified for the reference conceptual design phase. Final materials will be selected in later design phases.

Although heat-affected-zone hardness was not specifically addressed in the eference conceptual design phase, it will be considered in the weld development studies being performed as part of the advanced conceptual design phase. The Foreword or the revised text will state that heataffected-zone hardness was not adidressed in the design report.

The major factors considered in the design report with respect to general corrosion are considered in App. E. General corrosion will continue to be evaluated in later design phases. The Foreword will identify any major factors known to influence corrosion that are not addresseu in the design report.

Both linear and autocatalytic corrosion of carbon steel, under site-specific conditions, will be examined in later design phases, and appropriate literature reviews will be conducted. Site-specific conditions were not available for the reference conceptual design phase. 
Recommendation

13

\section{Resolution}

Hydrogen embrittlement and stress corrosion cracking in heat affected zones of weldments were not specifically examined during the reference conceptual design phase. These factors will be examined in later design phases. The Foreword will state that hydrogen embrittlement and stress corrosion cracking were not addressed in the design report.

Section B.4.4 of the design report gives the rationale for assuming a pitting factor of at least two, with the pitting factor being defined as the ratio of pit penetration to general corrosion. Temperature effects and stresses, both chemical and radiative, will be examined in later design phases. In

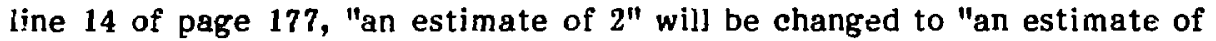
not less than $2 . "$

An improved data base will be developed during later design phases, after materials testing has been completed. Statistical analysis will be used, wherever applicable, to establish the maximum pitting depth. The Foreword will state that statistical analysis will be used, wherever applicable, in future analyses.

Section B.3.5 of the design report concludes that the direction of the effect of radiation on corrosion was generally uncertain. The effects of radiation under site-specific conditions will be summarized in later design phases.

The report will be revised.

Changing the assumption would require certain supporting documentation not developed in the reference conceptual design phase. In later design phases, a more complete data base, including material in the literature published after 1981, will be used to establish the makeup of the vapor phase.

Additional assumptions will be added to the list on page 104 of the design report.

Other materials are being considered in the materials testing program being conducted by ONWI. A materials option was not included in the work scope of the contract. Final materials will be selected in later design phases.

Extending the verification program is a funding- and schedule-related problem. The long-term testing planned will extend the program until the end of the retrievability period. 
Recom-

mendation

22

23

25

26

27

28

29

\section{Resolution}

A data base suitable for critically evaluating whether data obtained from seawater are relevant to brine at high temperature was not available at this stage of the design. A tropical seawater data base is recognized as inadequate for determining corrosion allowances for repository applications. The Foreword will state that information on the corrosion of steel by high-temperature brines, such as that presented in Casper and Pinchback (1980), * was not considered in the report.

A suitable corrosion allowance will be developed and documented in later design phases, after materials tests are complete. The Foreword will state that the final corrosion allowance will be developed from site-specific sait and brine data.

The ongoing test program will include tests of welds and heat affected zones. The Foreword will state that tests of welds and heat affected zones will be included in the test program.

The effects of pitting and crevice corrosion, stress corrosion cracking, and hydrogen embrittlement will be considered as the design progresses through the various design phases.

The effects of radiation are currently included in the test program. The results of the tests and how the overpack is affected will be evaluated in later design phases, including the concept of pitting potential. The Foreword will state that the effects of radiation on corrosion kinetics, protective films, and species production will be examined in later design phases.

Statistical analysis will be used to establish the maximum pitting rate, wherever applicable, in future design phases.

ONWI will review the subject area identified by Argonne to determine whether changes are required.

Testing has been conducted at $90^{\circ} \mathrm{C}$ and $150^{\circ} \mathrm{C}$. Tests at $250^{\circ} \mathrm{C}$ are included in the test program.

A procedure will be developed in later design phases to extrapolate test results to 1000 years.

*Casper, L.A., and T.R. Pinchback, eds., 1980, Geothermal Scaling and Corrosion, Special Technical Publication 717, American Society for Testing and Materials, Philadelphia. 
Recom-

mendation

31

32

\section{Resolution}

The references reflect the information available at the time of the reference conceptual design phase. The Foreword will state the time frame of the design effort.

Stress-gradient migration was not specifically covered in the reference conceptual design phase. The importance of all known brine migration mechanisms will be considered in future design phases. The Foreword will state that the brine migration data in the design report are not current and will be updated in later design phases.

The relative and absolute amounts of water from all sources will be established when site-specific conditions are defined. This information will be incorporated into later design phases. The Foreword will state that the absclute and relative amounts of water will be established in future design phases.

The Foreword will state that the effects of radiation on site-specific brines will be established in a later design phase.

The 30-L quantity is an estimate based on work previously reported in a repository conditions study (Office of Nuclear Weste Isolation, ONWl-483, 1980). The reference list will be modified to show this. The Foreword will state that the exact amount of brine transferred will be developed in later design phases.

The phrase will be deleted.

Leach testing will be performed by ONWI. A suitable test matrix will be provided as part of the program.

The cladding was not assumed to provide additional protection because of uncertainties regarding the condition of the cladding. This conservative approach will be maintainec through future design phases. The Foreword will state that cladding was not considered as protection in the reference conceptual design phase.

The sentence referred to on page 73 of the design report will be modified or deleted.

The assumptions will be verified and demonstrated in later design phases.

The Avery Island mine heater test results will be considered in a later design phase. They were not specifically considered in the reference conceptual design phase. 
Recom -

mendation

42

43

\section{Resolution}

Site-specific properties for salt will be available in later design phases. The thermal expansion characteristics of the host rock will be determined as part of the test program.

Improved models, which will be available in a later design phase, and future design considerations will provide a more realistic analysis of heat transfer.

Argonne's detailed concerns and recommendations on retrievability presented in Sec. 4.6 of the review report will be carefully considered in future design phases. For the present, removal of the waste form and canister was considered to be the better of the two available options. Inspection of the overpack after removal of the waste form is an issue separate from retrieval of the high-level waste. Exposure to radiation will be considered in designing the handling and transfer equipment.

Later design reports will use Sl units. Changing the design report to reflect Sl units is not considered necessary.

A glossary, to include a list of acronyms, will be added.

The proposed Foreword will satisfy this recommendation.

The recommendation will be followed.

The new terminology will be used in future design reports.

The design requirements are specified in Sec. 3 of the design report. The design can satisiy those requirements, subject to verification of the assumptions and considerations.

Changes to the text in response to this recommendation are noted in the next section of this appendix, which presents the resolution of the page-oypage comments.

Sources of data will be referenced if references are available. Outstanding examples are identified in the next section of this appendix, which presents the resolution of the page-by-page comments. 


\author{
Comment \\ Page Line(s) \\ iii 2-6 The sentence will be revised to accommodate the phrase "to baseline \\ the design." \\ iii 13-14 The definition of "waste package" will be corrected to agree with the \\ text on page 5 of the design report. \\ iii 29 The word "(baselined)" will be deleted. The term "baseline" will be \\ defined in a glossary. \\ $4 \quad 30-32 \quad$ The phrase "the waste form" will be deleted. \\ $7 \quad$ No change is recommendecl. The units, abbreviations, and terms used \\ in the design report will be tefined in a glossary. \\ 742 The net weight "9810" $\mathrm{kg} U$ uncier the CHLW column will be deleted, \\ but the asterisk will remain. \\ 9 10-11 The word "additional" will be deleted, and ", in addition to ONWI- \\ 438," will be inserted after the word "report." \\ $9 \quad$ 18-20 This sentence will be deleted. \\ $12 \quad 27$ No radiation limits are set for the overpack. The waste form \\ parameters cover radiation. \\ 214 The word "interface" in lines 1 and 2 will be deleted, and "areas" will \\ be substituted for "interfaces" in line 4. \\ $21 \quad 17,25$ Design of the glass waste canisters was not part of the reference \\ conceptual design phase. No change is recommended. \\ $21 \quad 18,25$ Table $3-5$ reflects drop requirements for the complete waste \\ package. No change is recommended. The fill height of the glass \\ waste canisters was specified by the designers of the packaging \\ facilities and is considered a basis for design. The fill limit on page 4 \\ of the design report will be corrected. \\ $22 \quad 7 \quad$ Yes. No change is recommended.
}




\section{Comment}

Page Line(s)

\section{Resolution}

The canister wall thicknesses will be added to the appropriate: figures. The power output from anything other than the waste for $n$ is insignificant and will not be reflected in the table.

The conversion of Gray to millirem will be added to a glossary. "Neutrons, reflected" is standard nuclear terminology.

The phrase "with a circular envelope" will be deleted.

The word "estimated" will be substituted for "provided" in line 10.

The phrase "intended for" will be inserted before "short-term."

The phrase "subject to stress corrosion cracking due to a thermal expansion differential relative to the waste glass" will be changed to "subject to stresses introduced by thermal expansion of the canister relative to the waste glass."

Approximate depths will be added. Also, the initial temperature of the salt will be added to the table.

A footnote will be added that references ONWI-423.

Yes, as shown in Fig. 4-5. No change is recommended.

The term "pitch" will be changed to "spacing."

Design of the glass waste forms was not included in the work scope of the contract. The degradation process will he evaluated in future design phases.

An appropriate reference will be added to the text. Sensitization occurs as a result of chromium depietion caused by chromium combining with carbon to form chromium-carbide at grain boundaries.

Failure of the waste package is defined as the loss of containment of radionuclides contained within the waste form. Nu change is recommended.

Shieided storage is understood to be storage with shielding to control the release of radiation. No change is recommended. 
Comment

Page Line(s)

$37 \quad 4-5$

$37 \quad 29$

39

19 Appendix $\mathrm{C}$ outlines the basis for assuming no air gap. The overpack surface temperature would be affected if an air gap were assumed. No change is recommended.

$48 \quad 25-26$

48 26-29

$49 \quad 3-6$

58

$18-19$

$58 \quad 29-31$

The sentence will be deleted.

As stated in the text, these values were assumed. No change is recommended.

The retrieval period is not long, and the bulk of the corrosion allowance will still be available to resist buckling. No change is recommended.

The sentence will be revised to read: "The inspection technique is expected to detect any flaws that could propagate as a result of structural loading or that could provide sites for accelerated crevice corrosion. Flaws below that detection limit are not expected to propagate and contribute to containment loss."

This assumption will be verified after the material corrosion testing program is completed. No change is recommended.

The phrase "(see Tables 3-1 and 3-2)" will be added after "these limits."

The sentence will be revised to read: "It can be determined from Fig. 4-5 that the repository areal thermal loading of $20 \mathrm{~W} / \mathrm{m}^{2}$, or 80.9 $\mathrm{kW} / \mathrm{acre}$, is well below the repository limit of $120 \mathrm{~kW} /$ acre for this waste form."

A footnote with the following wording will be added: "Refer to Sec. 5 -- Perforinance Description."

Leaching data for waste forms were not developed as part of the reference conceptual design phase. Leaching tests on the waste forms will be conducted to provide these data. No change is recommended.

See response to comment for page 59.

The $375^{\circ} \mathrm{C}$ temperature was specified as a limit for the CSF waste form. Evaluation of the waste form at lower operating temperatures was not requested. No change is recommended. 


\section{Comment}

Page Line(s)

62

$64 \quad 9-10$

$\begin{array}{ll}65 & 8\end{array}$

$65 \quad 8-11$

$65 \quad 26-32$

65

66

18-19

66

68

71

$71 \quad 17-29$

\section{Resolution}

See response to comment for page $\mathbf{5 9}$.

The reference conceptual design did not differentiate between base metal and weld metal. Localization of attack will be evaluated when the weld is developed.

The local corrosion effects will be developed after completion of the materials test program. No change is recommended.

The only data available at the time the design report was prepared were from studies in saline waters. Tests in brine are included in the test program for the waste package program. No change is recommended.

The phrase "which does not affect structural capability" will be deleted.

The phrase "(i.e., buckling)" should be added after the word "capability."

The phrase "as can be deduced from the ASME Boiler and Pressure Vessel Code" will be added.

Same resolution as given for lines $18-19$ just above.

Only one material was considered in the design report. No change is recommended.

See response to the cornment for page 68.

The text will be corrected to specify the "Westinghouse, 1982b" report.

The phrase "lead to the expectation that" will be substituted for "are considered adequate justification to expect." Release rates for the glass waste were provided by ONWI as design data. Verification of leach rates will be part of the test program.

Same resolution as given for page 71 , lines 17-29.

In line 13 ; "mitigating factors" will be changed to "considerations."

18,32 The assumption that fluids are stagnant will be verified as part of the overall site characterization program. 
Comment

Page Line(s)

72 31-34 The words "expected repository" will be substituted for "the stagnant, anoxic brine."

73 10-13 This possibility is being investigated further. The effects of radiation on the waste form were not addressed in the design report but will be in the test program.

73

17 The sentence will be deleted.

$73 \quad$ 19-22 Wording will be revised or deleted.

77

78

85

$12-13$

87

89 $2-3$

This assumption is acceptable for a conceptual design analysis. Rod contact will be evaluated in detail in later design phases. No change is recommended.

99 24-27 Testing will be integrated. No change is proposed.

$99 \quad 27-33$

The beginning of the sentence will be changed to read: "On the basis of this estimation, CFS would not constitute...."

Substantial plastic flow of the barrier material. No change is recommended.

The following sentence will be inserted af ter the first sentence: "It is recognized that publicly available codes must be used in any licensed design." Also, references will be added for the codes listed.

The data characterizing spent fuel will be upgraded during later design phases. No change is recommended.

Standardized waste packages are a design goal, and the major dimensions of the spent fuel assemblies used in the design report were based on the available data.

Changes in rod diameters caused by creep were not specifically covered in the reference conceptual design phase. Such changes will be considered in later design phases. No change is recommended.

The materials test program provides for determination of sitespecific conditions. Also, corrosion-related testing under sitespecific conditions is planned. Finally, to avoid major design changes, a weld development program is scheduled at the start of the advance conceptual design. 


\section{Comment}

$\underline{\text { Page }} \underline{\text { Line(s) }}$

$100 \quad 18$

$100 \quad 18-20$

100

101

$101 \quad 19$

$101 \quad 27-28$

101

102

102

$103 \quad 10-17$

Site-specific data will be provided for later design phases. No change is recommended.

0.75 weight percent. Other sources of water will be evaluated in later design phase. No change is recommended.

A reference supporting tia assumed water content will be added.

A period will be placed after "independently." The word "since" will be changed to "it is assumed that."

The effects of radiolysis will be studied in greater detail in future design phases. No change is recommended.

Verification and validation of computer programs will be included in later design phases.

Back-up materials will be included in the program. Corrosion testing is planned to continue through the retrieval period. No change is recommerıded.

104 The missing assumptions will be added to the text.

105 3-5 Pressure will be considered as a variable in future tests. No change is recommended.

Tests in solid salt were not identified during preparation of the design report. Tests in solid salt will be part of the in situ testing. No change is recommended. 
Comment

Page Line(s)

$106 \quad 8-10$

$106 \quad 25-29$

$106 \quad 29-30$

107 13-14 The sentence will be deleted.

$109 \quad 20$

$110 \quad 13-15$

$110 \quad 12-29$

110

$111 \quad 7$

111

111

112

$116 \quad 9-10$

116 recommended. is recommended. any, on the radiolysis products." be combined with the next paragraph. No change is recommended. increase in maximum press:ure...."

The expected brine conditions are site specific. No change is

\section{$\underline{\text { Resolution }}$}

Chemical stresses will be evaluated in later design phases. No change

The phrase "on the radical chain termination" will be changed to ", if

The term "blocking variable" will be defined in a glossary.

The sentence will be deleted. In addition, the previous sentence will

The text reflected the data available at the time the design report was prepared. Later data will be reflected in future design phases.

33 The term "backfill" will be defined, or another word will be used.

Leaching tests will be laboratory tests only. In the sentence starting on line 8, the word "preliminary" will be inserted before "list," and the word "reasonable" will be deleted.

16-18 Site-specific data will be provided. No change is recommended.

27-29 The value "60\%" will be deleted; sentence will begin with "An

The meaning of "surface/volume" will be explained in a footnote. Radiation is included in the planned test program. Fluid flow will be considered in later design phases. No credit is taken for the rod cladding. A detailed test plan will be developed.

$116 \quad 18$

The term "triangular pitch" will be defined in a glossary.

The analysis considered radiation heat transfer between rods and canister, plus the fin effect. The effect of rod failures in the canister will be evaluated in later design phases. No change is recommended.

118 Data were not available at the time. No change is recommended. 
Comment

Page Line(s)

$119 \quad 14,23$

$119 \quad 29-31$

120

120

120

$124 \quad 26-28$

$125 \quad 1-2$

26-27 The words "relatively easy" will be deleted.

129 The page number is 127 . The text will be corrected as suggested.

129 16-18 The statement was based on the author's experience in this field. The effect of carbon content will be demonstrated in a later design phase. No change is recommended.

12926 The statement disagrees with lines $8-9$ on page 63 of the design report. The difference will be resolved and the text revised as required.

133 5-6 The text will be revised to say that the accuracy of the statement is predicated on verification of all assumptions.

$133 \quad 7-10 \quad$ The word "reference" will be changed to "conceptual."

133 11-12 The words "economically attractive" will be changed to "technically feasible." 
Comment

Page Line(s)
18
The text will be corrected.

$141 \quad 26-27$

A reference will be added, or the last part of the sentence will be deleted.

$143 \quad 24-2$

The word "considered" will be inserted after the word "geology."

145 13-31 The sentence beginning on line 29 (Thus, disparate findings...) wili be deleted.

28 The reference list will be corrected.

147

1-9 The effects of radiolysis will be considered in future design phases, as will corrosion models and reaction mechanisms. Also, the last sentence in the first paragraph will be revised to read: "These equations have no reference to corrosion limits or to the actual mechanisms of the reaction."

$147 \quad 26 \quad$ A footnote will be added that specifies that the specific gravity of the brine is 1.2 .

$148 \quad 11$ The reference list will be corrected.

$14921 \quad$ Unexpected supplies of water and water aosorbed before closure by the host rock and crushed salt were not considered in the corceptual design. These phenomena will be evaluated in future design phases.

$150 \quad 25 \quad$ The heading in Table B-1 will be corrected.

150 The work was based on the data available at the time. Water quantities will be evaluated in greater detail in later design phases. No change is recommended.

$150 \quad 28-29$ No change is required.

$150 \quad 30-31 \quad$ No change is required.

153 15-19 These data were not considered in the conceptual design phase. Air and radiolytic species will be considered in a later design phase. No change is recommended. The phrase "but to the far more benign rate" will be reevaluated. 
Comment

Page Line(s)

155 12-14 The phrase "the ultimate consequences" (line 8) will be changed to "one possible ultimete consequence." Alternative hypotheses and further analysis will be addressed in future design phases.

157 18-19 The phrase "a reasonable estimate" will be changed to "an estimate."

158 2-4 The arguments presented will be verified in later design phases. If they prove to be erroneous, changes in design will be made to accommodate the correct argument.

$159 \quad 4 \quad$ The text wiil be corrected as suggested.

160 Radiation can affect the salt and influence corrosion of the package, and will be evaluated in later design phases.

$160 \quad 26 \quad$ The text will be corrected.

16323 The words "(Equation 5)" will be deleted, and "and radiolysis" will be inserted after "corrosion."

163 24-25 The words "seems remote" will be changed to "is redused." Deleting the sentence will be reevaluated.

16423 Data from 1984 were not available at the time. No change is recommended.

165 4-5 The references given in the footnote at the bottom of pase 164 are noted. Specific references will be added if available.

1655 New data will be evaluated in future design phases. No change is recommended.

165 10-14 Specific references will be added if available. The phrase "will drastically reduce" will be reevaluated.

165 20-31 New data will be evaluated in future design phases.

165 It was assumed that the host rock would return to its original state. Transpert of vapor and expulsion of nitrogen will be evaluated in later design pnases.

$166 \quad 3-6$
New data will be evaluated in future design phases. No change is recommended. 
Comment

Page Line(s)

$174 \quad 4-5$

$174 \quad 28$

$176 \quad 15-23$

$177 \quad 33$

180

$183 \quad 24-26$

189

10

$189 \quad 28-30$

$189 \quad 30-31$

$190 \quad 5-6$

190

$190 \quad 29$

$191 \quad 1-4$

191

8-12

$191 \quad 19 y-21$

\section{Resolution}

The last sentence of the first paragraph will be deleted.

The text will be corrected.

Lines 15-23 will be deleted, beginning with "It is judged, ...."

Lines 1-2 on page 180 state that testing may be required to establish this conclusion. Future testing will consider annealed and unannealed material, including welds. No change is recommended.

In line 25, the words "local corrosion" will be changed to "pitting corrosion." Also, the word "here" will be inserted af ter "regarded."

The inertness of corrosion products in the presence of radiation will be evaluated in later design phases. No change is recommended.

Only two mechanisms were modeled. All three mechanisms will be considered in future design phases. No change is recommended.

Improved models to be incorporated into later design phases will provide better relationships. No change is recommended.

Later data will be evaluated in future design phases. No change is recommended.

Later data will be evaluated ir future design phases. No change is recommended.

14 Standardized units will be used in future reports. No change is recommended.

The phrase "( 0.001 weight fraction)" will be changed to "( 0.75 weight percent)."

No codes were validated as part of the reference conceptual design phase. MIGRAIN is in the public domain. The codes were verified to the extent necessary for the conceptual design effort (see page 85 of the design report). No change is recommended.

The phrase "at the borehole boundary" will be deleted.

Water was assumed to be present as concentrated brine for this design phase. The source of water to the mudel was not a factor; only transport was considered. No change is recommended. 
Comment

Page $\underline{\text { Line(s) }}$

191 24-25 Knudsen flow was not considered in the conceptual design, but will be in future design phases. No change is recommended.

$192 \quad 1 \sim 23$

$196 \quad 1-3$

$200 \quad 19-26$

201

204

$12-14$

204

205

205

206

209

209

$214 \quad 1-3$

218

5

$219 \quad 14-15 \quad$ No change is required.

242

\section{6,21}

The

In lines 21 and 22 , the words "is clear" will be changed to "wis assumed," and "must be" will be changed to "is."

Model improvements in later design phases will provide for other parameters. No change is recommended.

The original comment was directed to lines 27-34, and the ONWI response was that the assumptions will be ranked as to importance in a later design phase. Sait compaction (referring to lines 19-26) will also be considered in a later design phase.

Figures D-2 and D-3 provide additional data. No change is recommended.

The sentence will bo deleted.

The revised text will explain the boundary values.

A reference will be added as a footnote.

SI units will be used in the next phase of design. No change is recommended.

Table D-3 will be corrected (actually page 207).

The term "triangular pitch" will be defined in a glossary.

The models will be improved in future design phases. No change is recommended. recommended.

The analysis considered neither the concentricity in the package nor the temperature drop through the oxide layers. No change is A footnote will explain that it was assumed that the temperature of the heads would not exceed $250^{\circ} \mathrm{C}$.

$42 \quad 1$

The data given in Cleary and Green (1967) will be evaluated, and any necessary changes in the text will be made. 
RESOLUTION OF ONWI RESPONSES TO THE PEER REVIEW PANEL'S RECOMMENDATIONS AND PAGE-BY-PAGE COMMENTS 


\section{$83 / 84$}

\section{Comment}

Page Line(s)

Resolution

$2436 \quad$ Page 241 will be corrected.

$244 \quad 20 \quad$ The table will be corrected.

$24421 \quad$ The table will be corrected.

\section{CONCURRENCES}

I concur with the responses, as presented in App. C, tc. the recommendations and comments of Argonne's review report entitled Radioactive Waste Isolation in Salt: Peer Review of Westinghouse Electric Corporation's Report on Reference Conceptual Designs for a Repository Waste Package.

J. A. Carr, Office of Nuclear Waste Isolation

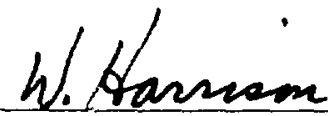

W. Harrison, Argonne National Laboratory

K. K. Wy, Salt Repository Project Office
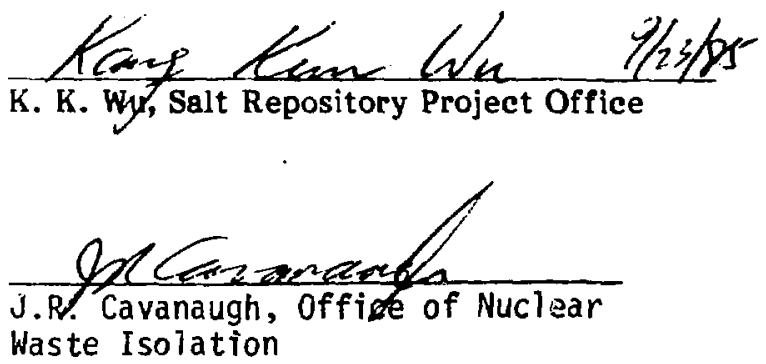


\section{Dougles F. Hambley}

Queen's University at Kingston: B.Sc., Mining Engineering (1972) Lewis University: MBA candidate Registered Professional Engineer, No. 18026014, Province of Ontario, and No. 062-039201, State of Illinois

Mr. Hambley has more than 10 years experience in mining, tunneling, and underground construction. He joined the staff of the Geoscience and Engineering Group of the Energy and Environmental Systems Division of Argonne National Laboratory in 1984. Prior to working at Argonne, Mr. Hambley was employed as a Senior Míning Engineer for nearly four years by Engineers International, Inc., a mining/tunneling consulting firm located in Westmont, Ill. In addition to designing several large tunnels for various purposes, he spent over two years as Project Engineer on U.S. Nuclear Regulatory Commission contracts to assess retrievability from repositories for high-level radioactive waste and to provide technical assistance for repository design reviews.

Between 1972 and 1980 , Mr. Hambley held variuus iechnical positions with major Canadian mining companies, including Denison Mines Ltd. and Falconbridge Nickel Mines Ltd. During his employment at Denison (1977-1980), he was esponsible for several major projects, including (1) a tripartite (Denison/Rio Algom/CAN $V_{i} E T$ ) regional stability study; (2) investigation, specification preparation, and tender evaluation for Stanrock Mine dewatering and shaft rehabilitation; (3) design of the backfill system for a pillar recovery scheme; aild (4) design of the underground garage and supply station for diesel fuel at No. 1 shaft.

Mr. Hambley has published on retrievability of high-level nuclear waste, design of shafts and tunnels, computer modeling of mine openings, and raise boring cost estimation. He is active in several technical societies. 


\section{Wyman Harrison}

University of Chicago: S.B., Geology (1953), after three years of undergraduate work at Stanford University

University of Chicago: S.M., Geology (1954)

University of Chicago: Ph.D., Geology (1956)

Registered Geologist, No. 2475, State of C.ilifornia

Certified Professional Geologist, No. 134, American Institute of

Professional Geologists, and No. 487, State of Virginia

Dr. Harrison is Associate Director for Geoscience and Engineering for Argonne National Laboratory's Energy and Environmental Systems Division. He directs a 25person group that performs analytical and experimental studies related to management of energy and mineral resources and to development and deployment of related technologies. Major activities of the group include (1) acquisition of geophysical and geotechnical data bases, (2) analysis of the data of geoscience to support design and deployment of energy technologies, and (3) development of physical and mathematical models of geophysical/geotechnical systems.

Dr. Harrison's group recentiy completed comprehensive surveys of geoseience data pertaining to crystalline rock complexes in the northeastern and Lake Superior regions of the United States to help assess their potential as possible sites for repositories for high-level radiogctive waste. Dr. Harrison has conducted numerous other geological and geotechnical studies at Argonne, ranging from estimating the petroleum resources of selected basins in the Soviet Union to determining near-shore circulation in Lake Michigan.

From 1971 to 1975 , Dr. Harrison was Professor of Geography (Associate Department Chairman) at the University of Toronto, where he specialized in geophysical studies related to slope stability in sedimentary terrains and the siting of supertanker ports. Prior to that, he was Associate Director for Physical, Chemical, and Geological Oceanography at the Virginia Institute of Marine Science and a Professor of Marine Science at the University of Virginia. Dr. Harrison was Director of Environmental/ Science Services Administration's (now National Oceanie and Atmospheric Administration's) Land and Sea Interaction Laboratory from 1964 to 1968. Before that he was on the faculty of Dartmouth College's Department of Geology and a geologist with the Indiana Geological Survey.

An author of over 100 papers, reports, reviews, and books, Dr. Harrison was made Senior Scientist at Argonne in 1976. 


\section{Amy B. Hull}

Iowa State University: B.S., Biochemistry/Chemistry (1980)

Northwestern University: M.S., Geology (1984)

Northwestern University: Ph.D. candidate

Ms. Hull is a Student-in-Residence in Argonne National Laboratory's Energy and Environmental Systems Division. Her doctoral research concerns the theoretical and experimental analysis of the geochemistry of brines in rock salt under thermal and gamma radiation fields. This work includes modeling the solubility and dissolution behavior of rock salt through a multicomponent electrolyte system ( $\mathrm{Na}-\mathrm{K}-\mathrm{Mg}-\mathrm{Ca}-\mathrm{SO}_{4}-$ $\mathrm{Cl}-\mathrm{H}_{2} \mathrm{O}$ ) at elevated temperatures with varying exposures to gamma radiation. Special emphasis is placed on the near-field environment of the nuclear waste repository at the Waste Isolation Pilot Plant site. The research is intended to illuminate phenomena that accentuate problems of brine migration in a repository environment.

Since 1983, as a graduate research assistant with Professors Abraham Lerman and Fred Mackenzie, Ms. Hull has been studying the problems of toxic versus essential environmental concentrations of micronutrients and has been modeling the geochemical cycling of these micronutrient trace elements. In 1982 she conducted experimental studies with Professor John Walther on high-temperature solubilities of clay minerals. Before attending Northwestern University, Ms. Hull worked for NALCO Chemical Company (1981) as a Chemist/Project Leader, researching the formation and removal of sulfur oxides from flue gases.

Ms. Hull is author and coauthor of numerous publications dealing with the morphology, growth, and stability of anhydrite and gypsual under various sedimentological conditions and her studies of $\mathrm{SO}_{2} / \mathrm{SO}_{3}$ at $\mathrm{NALCO}$. She is a member of three professional and honorary chemical societies. 


\section{Jerome Kruger}

Georgia Institute of Technology: B.S., Chemistry (1948)

Georgia Institute of Technology: M.S., Chemistry (1950)

University of Virginia: Ph.D., Physical Chemistry (1953)

Dr. Kruger is a Professor of Materials Science and Engineering, and Chemical Engineering, at Johns Hopkins University. After being with the Naticnal Bureau of Standards Corrosion Division since 1955, he spent 1983-1984 as a Lady Davis Fellow in Materials Engineering at the Technion-Israel Institute of Technology. From 1952 to 1955, Dr. Kruger was a chemist for the Naval Fesearch Laboratory.

Dr. Kruger is an expert on corrosion. His research has covered such topies as corrosion electrochemistry, localized corrosion, stress corrosion cracking, and ellipscmetric studies of the oxidation and preservation of metal surfaces. He has taught several extension courses on these topics at universities across the United States and has been an invited lecturer at more than 60 universities and conferences around the world. In November 1984, Dr. Kruger served on an ad hoc corrosion panel of the National Materials Advisory Board. Before that he had served on a working group organized by ONWI. Both of these bodies were concerned with corrosion testing of alloys for use in repositories for nuclear waste. He was also a member of $\varepsilon$ National Academy of Sciences panel established to evaluate the Swedish plan KSB-2 :or nuclear waste burial.

Dr. Kruger has published more than 90 papers and has been the editor of five books on corrosion. He is active in several professional societies, including having served as Chairman of the Corrosion Division of the Electrochemical Society; as President of the Federation of Materials Societies; as National Treasurer of the Electrochemical Society; and on the Board of Directors of National Association of Corrosion Engineering. In 1978 he served as the U.S. delegate to the International Corrosion Council and was elected First Vice President in 1984 (succeeding to the presidency in 1987). 


\section{Digby D. Macdonald}

University of Auckland, New Zealand: B.Sc., Chemistry (1964)

University of Auckland, New Zealand: M.Sc., Chemistry (1966)

University of Calgary, Canada: Ph.D., Chemistry (1969)

As Director of the Chemistry Laboratory, Physical Sciences Division, SRI, Dr. Macdonald specializes in electrochemistry, corrosion science, and nizthematical modeling of physical systems. His research on the corrosion of metals has involved fundamental studies on metal dissolution, stress corrosion cracking, corrosion fatigue, localized corrosion, activity transport in nuclear reactors, and thermodynamic and electrochemical phenomena in aqueous systems.

Dr. Macdonald has also served as Director and Professor at the Fontana Corrosion Center, Ohio State University, and Honorary Associate Professor of Chemistry at the University of Calgary. He was also Senior Researeh Associate for Alberta Sulfur Research, Ltd., and Assistant Research Officer for Atomic Energy of Canada, Ltd.

Dr. Macdonald has published more than 150 papers in scientific journals, books, and conference proceedings. He is also author of a book on transient techniques in electrochemistry, approximately 50 technical reports, and three patents and numerous patent disclosures. He has delivered more than 100 presentations on his research topics. He belongs to three professional societies and has served on two National Academy of Sciences committees. 


\section{Donald M. Rote}

Cleveland State University: B.E.S., Engineering Science (1960)

Case Western Reserve: M.A., Theoretical Physics (1963)

Case Western Reserve: Ph.D., Theoretical Nuclear Physies (1967)

Dr. Rote began his career as a professional physicist before leaving graduate school by serving as a part-time employee and consultant to Clevite Research Center, where he conducted experimental studies of the electromagnetic properties of PZT ceramics. After completing his graduate education, he first served as a postdoctoral fellow and later as an assistant professor in the Physies Department of the University of Illinois at Chicago. During that same period, he served as a consultant to the Physies Division of Argonne National Laboratory, where he conducted basic research in nuclear physies. In 1970, he became a full-time staff member of Argonne.

During his tenure as a physicist at Argonne, he shifted his emphasis to applied research problems. He has served as principal investigator on numerous research and assessment programs sponsored by the U.S. Environmental Protection Agency, U.S. Air Force, and Federal Aviation Administration concerned with development, verification, validation, and documentation of models used for air pollution assessment. He has also directed a number of field programs that required acquisition, analysis, and interpretation of air-quality, meteorological, and source data. Dr. Rote has concurrently served as an advisor on model validation, model applications, monitoring, and data analysis techniques to the above agencies. He formed and served as leader of the Air Resources Section from 1976 to 1983 . He served as Director of the A.tmospheric Impact Assessment Study of the proposed DOE Satellite Power System from 1978 to 1980. This program involved studies of chemical and electromagnetic interactions in the ionosphere and magnetosphere.

Dr. Rote is currently a member of the Geoscience and Engineering Group, where he serves as a core peer review panelist for the radioactive waste repository in salt program. During the past two years, he has conducted reviews of numerous models proposed by DOE contractors for use in performance assessment of waste package and repository designs. He has also reviewed several technical reports concerned with the corrosion testing of waste package materials and with the mathematical methods used in the analysis of accelerated life test data. Concurrently, he has served as a member of the laboratory director's task force for the development and application of electromagnetic technology to the continuous casting of sheet steel. As part of that group, he has been responsible for the conceptual design of both laboratory bench-scale and full-scale systems for handling and electromagnetically shaping molten metals.

Dr. Rote has authored or coauthored 70 reports, book chapters, and articles. 


$$
85 / 86
$$

APPENDIX D

CREDENTLALS OP PEER REVIEW PANEL MEMBERS 
James E. Russell

South Dakota School of Mines and Technology: B.S., Civil Engineering (1963)

South Dakota School of Mines and Technology: M.S., Civil Engineering (1964)

Northwestern University: Ph.D., Theoretical and Applied Mechanics (1966)

Professor Russell joined the faculty of Texas A\&M University in 1978 as Professor of Mining Engineering and Geophysics, and has been a Brockett Professor of Engineering since 1982. He has had extensive experience in the analytical/numerical, laboratory, and field rock mechanics aspects of mining, undergroand construction, and underground storage. Much of his research has involved in situ experiments related to waste repository design, radioactive waste isolation in salt, creep models for salt, thermal loading in waste repositories in salt, benchmark problems in salt using different numerical methods, coal gasifjeation, and lignite mining.

Dr. Russell currently serves as rock mechanies consultant to ONWI and Oak Ridge National Laboratory; resource consultant for rock mechanics to the Overview Committee for the Basalt Waste Isolation Project; coinvestigator of an ONWI-sponsored project at Texas A\&M University to develop constitutive equations for salt; and member of the Performance Constraints Working Group for RE/SPEC, Inc., and ONWI. During 1979 he served as a member of the Peer Review Group for DOE, Nevada Nuclear Waste Storage Investigations.

From 1972 to 1976 , he was Vice President and Resident Consultant at RE/SPEC, [nc. From 1977 to 1978 , just prior to accepting the position at Texas A\&M, Professor Russell was the Project Manager for Rock Mechanics at the Office of Waste Isolation, Union Carbide Corporation. From 1967 to 1976, Dr. Russell served as Assistant Professor of Civil Engineering; Associate Professor of Civil Engineering, Mining and Civil Engineering, and Mining Engineering; and Professor of Mining Engineering at the South Dakota School of Mines and Technology. From 1966 to 1967, he was Senior Research Engineer at Southwest Research Institute.

Professor Russell has published extensively in the fields of rock mechanics, mining engineering, lignite mining, coal gasification, and waste isolation. He is a member of six professional and honorary societies, and has served on 11 national committees. 


\section{Gary S. Was}

University of Michigen: B.S., Nuclear Engineering (1975)

Massachusetts Institute of Technology: S.M., Nuclear Engineering (1977)

Massachusetts Institute of Technology: Sc.D., Nuclear Materials Engineering

(1980)

After a year of postdoctoral research at the Massachusetts Institute of Technology, Dr. Was became Assistant Professor in the Department of Nuclear Engineering at the University of Michigan. From 1978-1980, he was a Staff Scientist for Entropy, Ltd., where he was a cocontributor to the development of a fuel performance and reliability computer code system. He also spent a summer (1974) working for the U.S. Environmental Protection Agency on developing a model for radiation transport through effluent pathways.

Dr. Was conducts research on the effects of impurities on the susceptibility of austenitic alloys to intergranula: cracking at both high and low temperatures in aqueous environments, and on the effect of ion beam mixing on the physical and mechanical properties or alloy surfaces. His achievements have included significant advances in the understanding of the chromium depletion phenomenon in nickel-base alloys, the quantitative characterization of the electrochemical behavior of chromium-depleted zones in austenitic alloys, and the development of models to measure the performance of stainless steel fuel cladding in light-water nuclear reactors.

Dr. Was is author and coauthor of more than 18 publications and has presented his research at 12 conferences. He is a member of nine professional and honorary societies. 